\title{
DYNAMIC ANALYSIS OF STRUCTURES
}

\author{
Athol J. Carr ${ }^{1}$
}

\begin{abstract}
This paper is the result of discussions of the study group on Dynamic Analysis established by the New Zealand National Society for Earthquake Engineering and whose brief was to provide some guidance to design engineers on the usage of the dynamic analysis methods that are becoming more common in structural design with the stricter requirements of the seismic loadings requirements of NZS 4203:1992. The paper first of all discusses the concepts of dynamic analyses of single mass systems and then extends this to the modal analysis methods for the analyses of multi-mass systems. The paper then covers a variety of aspects that may be of concern in performing the dynamic analyses and in the modelling of structures.
\end{abstract}

\section{WHY CARRY OUT DYNAMIC ANALYSES?}

Consider the single degree of freedom cantilever structure shown in Figure 1 where the mass $M$ is supported on the top of the weightless column of length $\mathrm{L}$ and lateral stiffness $\mathrm{K}$. If the column was prismatic with a flexural rigidity of $\mathrm{EI}$, where $E$ is Young's Modulus and $I$ is the second moment of area of the section, then the stiffness $\mathrm{K}$ would be $3 \mathrm{EI} / \mathrm{L}$. If a lateral force $\mathrm{P}$ is applied to the top of the column, then the lateral deflection $\mathrm{x}$ at the top would be obtained by solving the equation

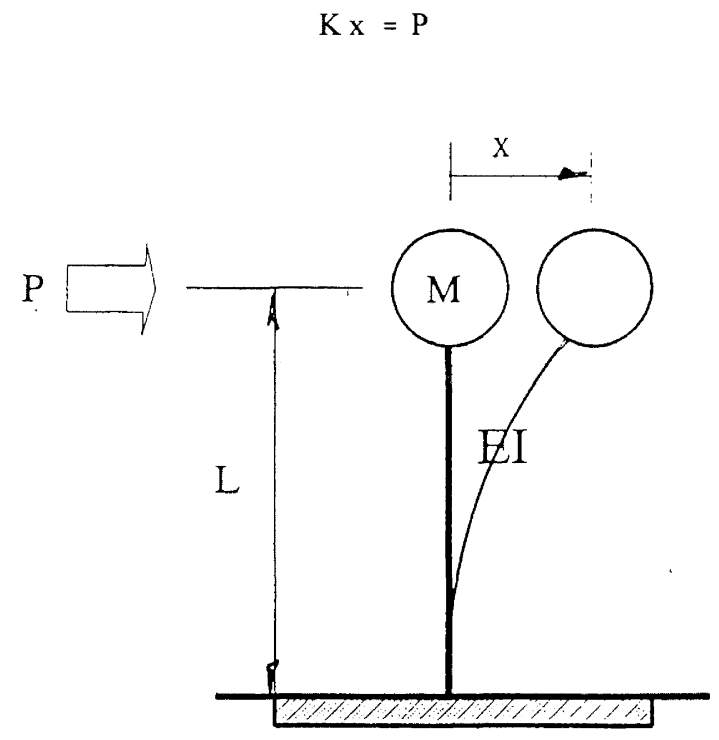

Figure 1. Single Degree Of Freedom Model of a Structure.

1 Department of Civil Engineering, University of Canterbury, Christchurch (Fellow)
In the majority of analyses carried out by engineers the forces are treated as static and even in situations where the forces are not actually constant with time they are considered to change sufficiently slowly that dynamic effects are not significant. If the force $\mathrm{P}$ acting on the structure changes at such a rate that the inertial and damping forces have a significant effect on the equation of equilibrium, then a dynamic analysis is required.

In a dynamic analysis where the applied force $\mathrm{P}(\mathrm{t})$ is changing with time, the unknowns are the displacement, velocity and acceleration of the mass but there is only a single equation of equilibrium, albeit a second order ordinary differential equation,

$$
\mathrm{M} \ddot{\mathbf{x}}+\mathrm{C} \dot{\mathrm{x}}+\mathrm{Kx}=\mathrm{P}(\mathrm{t})
$$

where the dot denotes differentiation with respect to time.

In the case of an earthquake excitation, the external forces are, in fact, constant but the ground on which the structure is located is moving. If the foundation of the structure can be considered to move as a rigid body when subjected to a ground displacement $\mathrm{x}_{\mathrm{g}}$ then the following observations may be made. The inertia force acting on the structure is proportional to the total acceleration, i.e. the sum of the acceleration of the structure and the acceleration of the ground. The elastic force in the structure is proportional to the deformation in the structure, i.e. the displacements of the mass relative to the foundation. It is generally assumed that the damping force is also proportional to the relative velocity in the structure, i.e. the velocity of the structure mass relative to the foundation. This is expressed in the following equation.

$$
\mathrm{M}\left(\ddot{\mathrm{x}}+\ddot{\mathrm{x}}_{\mathrm{g}}\right)+\mathrm{C} \dot{\mathrm{x}}+\mathrm{Kx}=\mathrm{P}(\mathrm{t})
$$

This equation may be re-arranged to give

$$
M \ddot{x}+C \dot{x}+K x=P(t)-M \ddot{x}_{g}
$$


In this case the applied force $\mathrm{P}(\mathrm{t})$ is constant and represents the static force $\mathrm{P}_{0}$ and the second term on the right hand side of the equation is often thought of as the equivalent earthquake force. This force is proportional to the mass of the structure and the ground acceleration. If the maximum acceleration of the ground is known the maximum equivalent lateral force can be computed and the maximum displacement of the structure can be found.

If the structure is allowed to freely vibrate with no external applied forces and no damping in a simple harmonic motion then the displacement has a sinusoidal variation with time such that

$$
x(t)=A \sin \omega t+B \cos \omega t
$$

where $A$ is the amplitude of the vibration and $\omega$ is the natural circular frequency of free-vibration whose units are radians per second. Substituting this solution into the equation of undamped motion yields

$$
-\omega^{2} M x+K x=0
$$

so that

$$
\omega=\sqrt{\frac{K}{M}}
$$

and

$$
\mathrm{f}=\frac{\omega}{2 \pi} ; \quad \mathrm{T}=\frac{1}{\mathrm{f}}
$$

where $f$ is the natural frequency (Hertz) and $T$ is the natural period (seconds) of free vibration.

In the above equations of free-vibration, the effects of damping have been ignored. In general, the observed equivalent amounts of damping in building structures appears to be small where the fraction of critical damping $\lambda$ is less than about $5 \%$. This means that the difference between the undamped natural frequency $\omega$ and the damped natural frequency $\omega_{D}$ is insignificant. If the structure has damping and if the damping coefficient $\mathrm{C}$ is defined as

$$
C=2 \lambda \omega M
$$

where $\lambda$ is the fraction of Critical Damping, then the response in a damped simple harmonic motion is

$$
x(t)=e^{-\lambda \omega t}\left\{A \sin \omega_{D} t+B \cos \omega_{D} t\right\}
$$

where the damped natural circular frequency $\omega_{D}$ is defined as

$$
\omega_{\mathrm{D}}=\omega \sqrt{1-\lambda^{2}}
$$

If the structure is linearly elastic, the Principle of Superposition is valid and the solution for the response under a combination of loads can be obtained by superimposing the response obtained from each separate load. Therefore the static force solution can be adued to that for the earthquake excitation. This paper will consider only the earthquake excitation response.

If the ground acceleration history is known, then the equation of motion may be re-written as

$$
M \ddot{x}+C \dot{x}+K x=-M \ddot{x}_{g}(t)
$$

Substituting for $\mathrm{C}$ and $\mathrm{K}$ and dividing through by $\mathrm{M}$ gives

$$
\ddot{x}+2 \lambda \omega \dot{x}+\omega^{2} x=-\ddot{x}_{g}(t)
$$

The solution for this equation can be shown [Clough, 1992] to be

$$
x(t)=-\frac{1}{\omega} \int_{0}^{t} \ddot{x}_{g} e^{-\lambda \omega(t-\tau)} \sin \omega_{D}(t-\tau) d t
$$

This solution is usually obtained by a numerical integration such as the methods of Newmark [Clough, 1992] etc.

An alternative approach to the solution for the structure subjected to the earthquake excitation is to use a response spectrum method where, given the natural period of freevibration and fraction of critical damping of the structure, the maximum displacement and maximum acceleration of the structure of the structure can be determined.

Most engineers are familiar with the use of Response Spectrum methods of carrying out the dynamic analyses of structures for design. These Response Spectrum methods reduce the dynamic response calculations to that of observing the maximum displacement or acceleration response of their structure to a given earthquake for which the spectrum has been determined or specified.

\section{RESPONSE SPECTRA}

Response spectra are derived from the response of a single degree of freedom system subjected to an earthquake ground acceleration excitation. The maximum absolute value of the displacement of the mass is obtained from

$$
x_{\max }=S_{d}=\frac{1}{\omega} S_{v}=\frac{1}{\omega^{2}} S_{a}
$$

where $S_{d}$ is the Spectral Displacement, $S_{v}$ is the Psuedo Spectral Velocity and $S_{a}$ is the Pseudo Spectral Acceleration. The Pseudo Spectral Velocity is the maximum value of the integral term above which is an integration of an acceleration with respect to time and therefore has the units of velocity. It is not the maximum velocity of the mass, the Spectral Velocity, but it is related to it. The Psuedo Spectral Acceleration usually differs from the Spectral Acceleration, which is the maximum total acceleration of the structure, by only one or two percent. The period used in the calculation of the modal response is that of the structure in undamped free-vibration. These spectra are usually published for several levels of viscous damping, usually $0 \%, 2 \%, 5 \%, 10 \%$ and $20 \%$ of critical viscous damping. Spectra in the various New Zealand design codes have been based on $5 \%$ of critical viscous damping. With the low levels of damping encountered in building structures the natural period is little affected by viscous damping.

The maximum value of the base shear $\mathrm{V}$ can be obtained from

$$
\mathrm{V}_{\max }=\mathrm{KS}_{\mathrm{d}}=\omega^{2} \mathrm{MS}_{\mathrm{d}}=\omega \mathrm{MS}_{\mathrm{v}}=\mathrm{MS}_{\mathrm{a}}
$$

The maximum displacement of a structure with a given natural period of free-vibration and a given fraction of critical damping subjected to the El Centro ground accelerogram shown in Figure 2, can be read off the Displacement Spectrum shown in Figure 3.

The maximum acceleration of the mass of the structure subjected to the El Centro ground accelerogram can be obtained from the Acceleration Spectrum for the El Centro accelerogram, shown in Figure 4. 


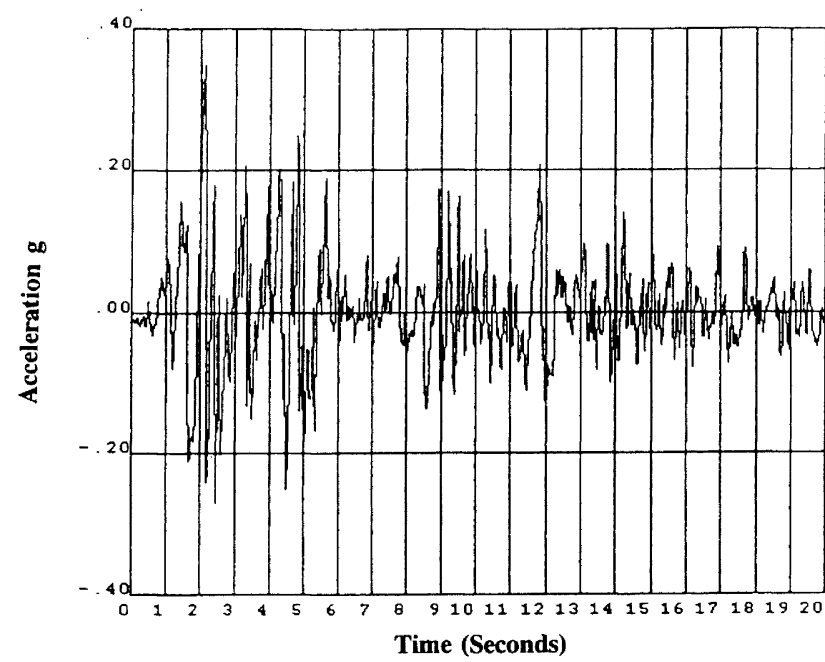

Figure 2. El Centro May 1940, North-South Accelerogram.

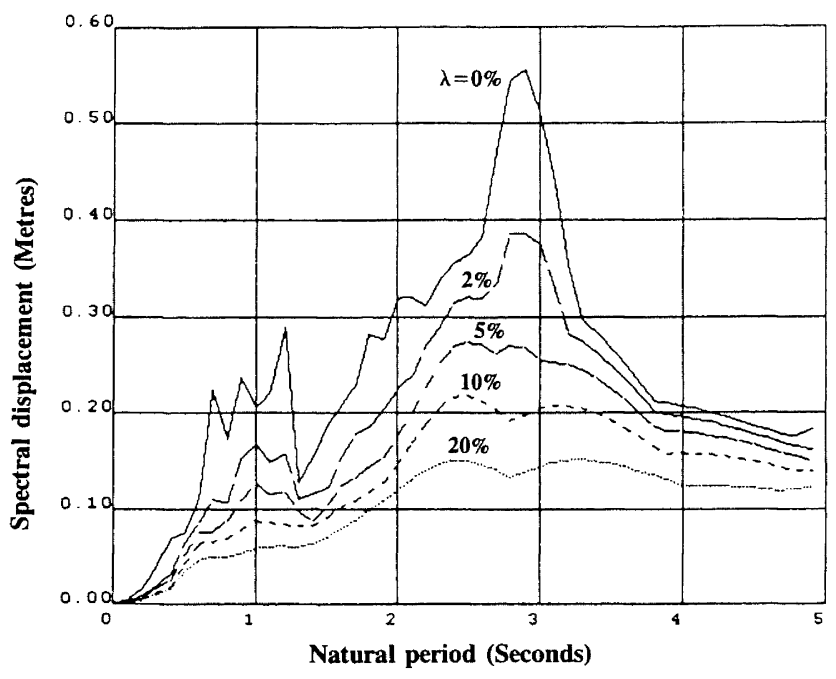

Figure 3. Displacement Response Spectrum.

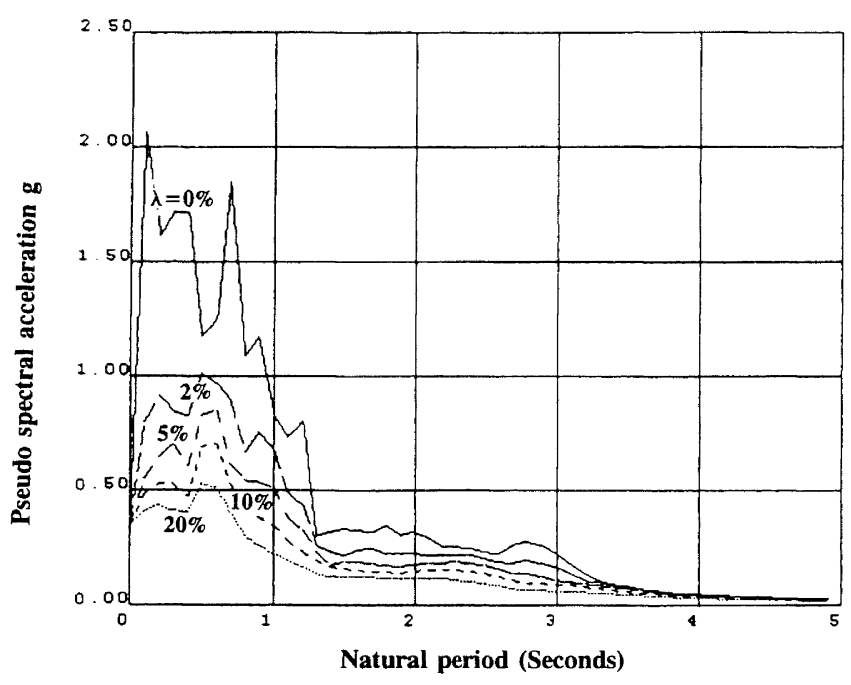

Figure 4. Pseudo Acceleration Response Spectrum.
The Code specified response spectra are smoothed response spectra based on an earthquake with a specified probability of exceedance during the expected design life of the structure. If a different level of risk is desired, or the expected life of the structure is much different from that of normal buildings, then the spectral values may need to be adjusted accordingly.

Many building codes supply the design acceleration spectra with the units being fractions of the acceleration of gravity so that the engineer may use the weight of the structure rather than the mass of the structure in computing the base shear.

However, these Response Spectrum methods are applicable only to single degree of freedom structures. For a multi-degree of freedom structure, which covers nearly all real structures, the answer requires the simultaneous solution for the displacements of every degree of freedom of the structure as a time-history. This time-history may then be enveloped to obtain the maximum values of the displacements and member forces. The displacement of the structure cannot now be described as a function of a single variable and the structure does not have a single natural frequency of free-vibration and so the simple application of response spectra techniques is no longer available to the designer. This means that for these structures a different approach must be made to their dynamic analyses. The following example of a building subjected to a horizontal ground motion will illustrate some of the differences in behaviour when compared with a single degree of freedom system.

\section{STRUCTURES WITH MORE THAN A SINGLE MASS}

For the structure shown in Figure 5, the ground is assumed to move initially to the right. The base of the structure has to move with the ground but upper parts of the structure have not yet followed the lower structure. It takes time for the shear forces, caused by the deformation of the structure, to accelerate the masses of the upper floors. The speed of propagation of the wave motion up the structure is governed by the stiffness of the stories and mass of the floors. By the time that the upper part of the structure has started to follow its base, the ground may well have started to move back in the reverse direction. The deformation pattern of the structure may take on a complex form.

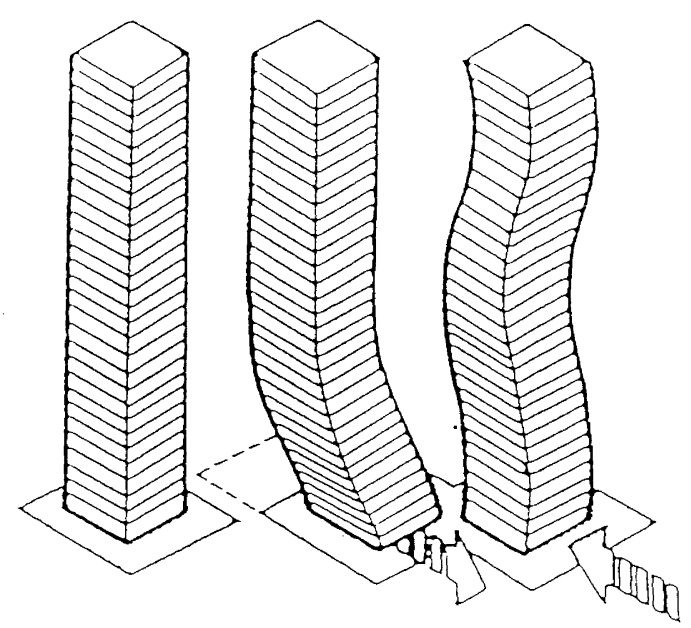

Figure 5. Structure subjected to ground displacement. 
The inertia forces acting on the various levels of the structure are proportional to the masses and total accelerations of the floors and are derived from Newton's Laws. These accelerations are the second derivatives of the displacements with respect to time and exhibit a much greater variation with respect to time than are shown by the displacements of the structure.

The number of degrees of freedom in a structure is defined as the number of variables required to uniquely define the inertia forces or the displacements. For any real structure with distributed mass, the number of degrees of freedom is infinite. However, most computational methods reduce the number of degrees of freedom by restricting the displacements of the members, or elements, within the structure to a limited class of functions. For example, for beam or column members in a conventional frame analysis, the lateral displacements of the beam are usually assumed to have a cubic variation along their length so that their displacements can be uniquely defined by the displacements of the joints, or nodes, at the member ends. In dynamic analyses, the number of degrees of freedom may be further reduced by lumping the mass of the structure at a selected number of joints or levels. Those degrees of freedom without mass are no longer independent variables but are dependent on the displacements of those degrees of freedom that do have mass associated with them.

In most building structures with stiff in-plane floor diaphragms the mass representation may be reduced to two horizontal inertias, the mass of the floor acting in two orthogonal horizontal directions, and a rotational inertia of the floor about a vertical axis, generally through the centre of mass of the floor. The latter is related to the polar moment of inertia of the floor mass about the vertical axis.

The equation of motion can now be written as

$$
[M]\{\ddot{x}\}+[C]\{\dot{x}\}+[K]\{x\}=\{P\}-[M]\{r\} \ddot{x}_{g}
$$

where $[M],[C]$ and $[K]$ are the mass, damping and stiffness matrices, $\{\mathrm{x}\}$ is the vector of displacements. The vector $\{\mathrm{r}\}$ is the influence vector for the ground displacement where each term is the displacement in the structure associated with a unit foundation movement in the direction of the earthquake excitation.

\section{MODAL ANALYSES}

The natural frequency of free vibration associated with a single degree of freedom system vibrating in simple harmonic motion has its equivalent in multi-degree of freedom systems. At each natural frequency of free vibration the structure vibrates in simple harmonic motion where the displaced shape, or mode shape, of the structure is constant but the amplitude of the displacement is varying in a sinusoidal manner with time. A system with $\mathrm{N}$ degrees of freedom has $\mathrm{N}$ natural frequencies of free vibration and $\mathrm{N}$ mode shapes of free vibration $\{\phi\}$, one associated with each natural frequency. This set of $N$ mode shapes forms a Basis set of displacement vectors in that any displacement shape of the structure can be made up of a combination of these linearly independent mode shapes. Luckily, most engineers are generally only concerned with a small number of these modes, i.e. those associated with the few lowest natural frequencies of free vibration.

When assuming simple harmonic motion the displacement in mode shape can be written as

$$
\{\mathrm{x}\}_{\mathrm{i}}=\mathrm{A}\{\phi\}_{\mathrm{i}} \sin \omega_{\mathrm{i}} \mathrm{t}
$$

where $\mathrm{A}$ is an, as yet, undetermined constant and the equation of undamped free-vibration becomes

$$
-\omega_{i}^{2}[\mathrm{M}]\{\phi\}_{\mathrm{i}}+[\mathrm{K}]\{\phi\}_{\mathrm{i}}=\{0\}
$$

The mode shapes, or vectors, have the very important property in that they are orthogonal with respect to the mass and stiffnesses matrices of the structure. This means that, provided one assumes that the mode shapes are also orthogonal with respect to the damping matrix of the structure, one can consider the structure vibrating in any of the modes of free vibration as a single degree of freedom system with the natural frequency, or period, of that mode. The normally coupled $\mathrm{N}$ degree of freedom system behaves as $\mathrm{N}$ single degree of freedom systems, each one associated with a natural mode of free vibration. The shape of each mode of free vibration is unique but the amplitude of the mode shape in undefined. The mode shapes are usually normalized such that the largest term in the vector is 1.0 as is shown in the top of Figure 6 . Alternatively the sum of the squares of the terms in the vector is 1.0 or, in the case of some of the computer programs in common engineering usage the vectors are normalized so that the generalized mass $\mathrm{M}^{*}$ is 1.0 i.e.

$$
\mathrm{M}_{\mathrm{i}}^{*}=\left\{\phi_{\mathrm{i}}\right\}^{\mathrm{T}}[\mathrm{M}]\left\{\phi_{\mathrm{i}}\right\}=1.0
$$

It must be noted in this last case that the 1.0 has the units of mass.

If the modes shapes are assumed to be orthogonal with respect to the damping matrix as well as the mass and stiffness matrices, then damping will have no effect on the mode shapes but the natural frequency for each mode will be the damped frequency as was discussed earlier for the single mass systems.

$$
\omega_{D_{i}}=\omega_{i} \sqrt{1-\lambda_{i}^{2}}
$$

where $\lambda_{i}$ is the fraction of critical damping in the $i$ th mode of free vibration.

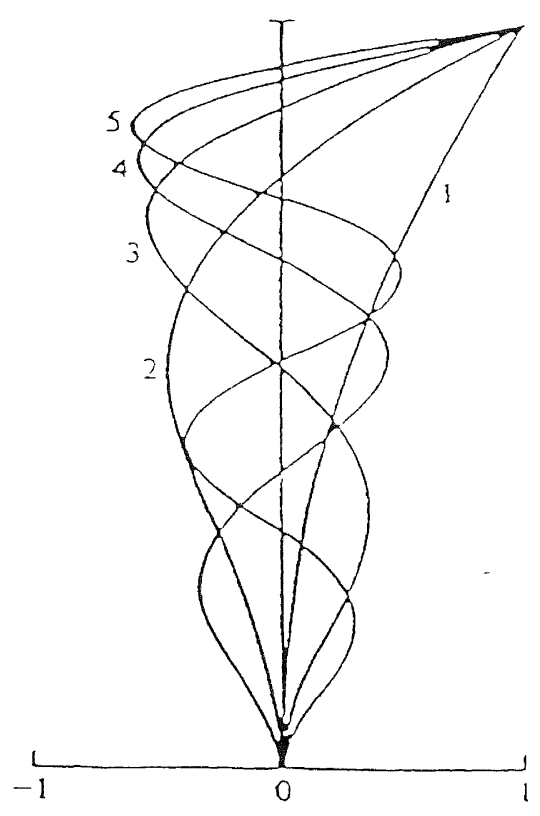

Figure 6. Mode shapes of free-vibration. 
If the structure has symmetry in both stiffness and mass with respect to two orthogonal horizontal axes of the structure, then the mode shapes will uncouple the motion in the two horizontal axis directions and it may be possible to speak of, say, $\mathrm{x}$ and $\mathrm{y}$ direction mode shapes as well as torsional modes. However, if these symmetries are not present and eccentricity of mass and/or stiffness is to be considered, then such a directional uncoupling is unlikely. This means that any translation of the structure in an axis direction will involve translation in the orthogonal direction and also rotation about the vertical axis. In design, even though the structure may appear to be symmetrical, this is not guaranteed by the materials and in the yield properties. This is one reason for code requiring designers to make provision in the design for some torsion about the vertical axis.

The uncoupling of the degrees of freedom means that one can use Response Spectra methods to obtain the response of each mode in the structure and thus for each mode obtain the displacements and accelerations or forces. The difficulty, however, is that Response Spectrum methods have lost parts of the information relevant to the dynamic behaviour of the structure. Unanswered questions are: when has the peak response occurred, what sign should be associated with it and what any other mode with a different natural frequency was doing at the time the peak response occurred in the mode of interest. It is thus impossible to combine these modal responses to obtain the maximum response of the multi-degree of freedom system. The problem is usually resolved by relying on a statistical combination of the modal responses. The most common method being the Square Root of the Sum of the Squares (SRSS) combination method which was used in the earlier New Zealand loadings codes.

These modal methods are only applicable to linearly elastic structures undergoing small deflection responses in that these are the requirements for the Principle of Superposition to be valid. If these conditions are not met, then the natural modes and frequencies of free vibration do not have a meaning because the frequency and mode shapes depend on the amplitude of the displacement and the resulting free vibration in each mode is no longer simple harmonic. Further, if the Principle of Superposition is no longer valid, then the combination of the modal responses to get the total structural response is also invalid.

\section{MODAL ANALYSIS USING RESPONSE SPECTRA}

The response of the structure in each mode can be written as

$$
\ddot{Y}_{i}+2 \lambda_{i} \omega_{i} \dot{Y}_{i}+\omega^{2} Y_{i}=-\frac{L^{*}{ }_{i}}{M^{*}{ }_{i}} \ddot{x}_{g}(t)
$$

where $Y_{i}$ is the amplitude of the $i$ th mode where the displacement of the structure in the $i$ th mode may be expressed as

$$
\{\mathbf{x}\}_{\mathrm{i}}=\{\phi\}_{\mathrm{i}} \mathbf{Y}_{\mathrm{i}}
$$

and

$$
\mathbf{L}^{*}{ }_{i}=\{\phi\}_{i}{ }^{T}[\mathbf{M}]\{\mathbf{r}\}
$$

To obtain the maximum displacement of the structure in the $i$ th mode, the procedure is very similar to that for the single degree of freedom system.

$$
\{\mathbf{x}\}_{\mathrm{i} \max }=\{\boldsymbol{\phi}\}_{\mathrm{i}} \frac{\mathrm{L}^{*}{ }_{\mathrm{i}}}{\mathrm{M}^{*}{ }_{\mathrm{i}}} \mathrm{Sd} \mathrm{d}_{\mathrm{i}}=\{\boldsymbol{\phi}\}_{\mathrm{i}} \frac{\mathrm{L}_{\mathrm{i}}^{*}}{\mathrm{M}^{*}{ }_{\mathrm{i}}} \frac{1}{\omega^{2}} \mathrm{Sa}_{\mathrm{i}}
$$

Once the displacements have been obtained for the $i$ th mode, then the inter-storey drifts, the member forces and moments can all be obtained for the $i$ th mode.

It can be shown that the maximum base shear for the $i$ th mode can be written as

$$
\mathrm{V}_{\mathrm{i} \max }=\frac{\left(\mathrm{L}_{\mathrm{i}}^{*}\right)^{2}}{\mathrm{M}^{*}{ }_{\mathrm{i}}} \mathrm{Sa}_{\mathrm{i}}
$$

and if the equivalent inertia forces $\{f\}_{i}$ associated with each degree of freedom is required, then they are given by

$$
\{f\}_{\mathrm{i} \max }=\frac{[\mathrm{M}]\{\boldsymbol{\phi}\}_{\mathrm{i}}}{\mathrm{L}^{*}{ }_{\mathrm{i}}} \mathrm{V}_{\mathrm{i} \max }
$$

These forces may be applied to the structure and actions evaluated with an equivalent static analysis. This is unnecessary with most modern programs as the member forces in the structure follow immediately from the computed displacements.

\section{Mass Participation Factors.}

The multiplier of the ground acceleration, $\mathrm{L}^{*} / \mathrm{M}^{*}$, in the equation of motion for the $i$ th mode, is the participation factor for the $i$ th mode of the structure. It is a function of the mode shape, the mass distribution of the structure, and the direction of the earthquake excitation. If the vibration components of the mode shape are orthogonal to the direction of the ground excitation, the participation factor for that mode is zero. Negative participation factors may also be observed. In general, the magnitudes of the participation factors diminish with increasing mode number and at some point it may be considered that the remaining higher modes do not significantly affect the displacements.

The participation factor shows how strongly a given mode contributes to the response of the structure when subjected to a specified direction of ground acceleration. An important point to note concerning participation factors is that the numbers obtained are dependant on the normalization method used in computing the mode shapes of free-vibration. Thus the participation factors computed from one computer program should not be compared with those from another program unless they both use the same methods of normalizing the mode shapes.. This normalization does not affect the solution for the displacements or member actions as the modal amplitude $Y_{i}$ has to be multiplied by the mode shape and any effect of the normalization is cancelled out. It is only the modal amplitude $Y_{i}$ that is affected by the choice of normalization method.

\section{Number of Modes to be Used.}

The number of modes needed depends on the structure, the direction of earthquake excitation and the degree of coupling between the translational and torsional modes. Sufficient modes should be used to ensure that most of the structure's mass is contributing to the excitation in each direction of excitation. One measure that can be used is to investigate the Participation Factors for each mode. These will show which modes are participating in the particular direction of excitation, 
which modes are orthogonal to the excitation and at which mode number the contributions from the higher modes are becoming insignificant.

A more significant method uses the Effective Mass of each mode $\left(\mathrm{L}^{\circ}\right)^{2} / \mathrm{M}^{*}$ which is seen in the expression for the maximum base shear in each mode. The sum of the effective masses for all modes must equal the total mass of the structure The effective mass associated with a mode usually diminishes rapidly as the mode number $i$ increases. The number of modes used in the analysis should be large enough so that the modes used represent at least $90 \%$ of the total mass of the structure.

\section{COMBINATION OF MODAL MAXIMA}

The use of response spectra techniques for multi-degree of freedom structures is complicated by the difficulty of combining the modal responses. The combinations are usually achieved by using statistical methods. Response spectra calculations have lost all information on sign or when the maximum displacement etc. occurred. Therefore, proper combinations of modes is not possible. In each mode structural members are in equilibrium and all actions in members have the appropriate of signs. However, what contribution or sign other modes should have at the same time are unknown.

Let $R_{i}$ be the modal quantity (Base Shear, Nodal displacement, Nodal force, Member stress etc.). Values of $R_{i}$ have been found for all modes (or for as many as are significant). Most design codes require designers to use a sufficient number of modes so that the error associated with the omitted modes is only a small percentage of the total response. NZS 4203 requires at least 3 modes in each direction to be considered.

$R_{\max }=\sum_{i=1}^{N} R_{i \max }$ would be true only if all maxima occurred at the same instant of time and all had the same sign.

In general,

$\mathrm{R}_{\max } \leq \sum_{i=1}^{N} \mathrm{R}_{\mathrm{i} \max }$ and in almost all cases the inequality holds.

There are several accepted statistical combination methods.

(a) Maximum Possible Response: Sum of Absolutes. This is very conservative and is very seldom used except in some codes for say two or three modes for very short period structures.

$$
\mathrm{R}_{\max }=\sum_{\mathrm{i}=1}^{\mathrm{N}}\left|\mathrm{R}_{\mathrm{i} \max }\right|
$$

(b) Maximum Likely Response: Square Root of Sum of Squares, SRSS or Root Sum Square. This is the most commonly used method. It is NOT Root Mean Square.

$$
\mathrm{R}_{\max }=\sqrt{\left(\sum_{i=1}^{N} \mathrm{R}_{\mathrm{i} \max }^{2}\right)}
$$

The Root Sum Square method was initially used when twodimensional structural analyses were the norm. In a twodimensional structure no two lateral frequencies are close, and so no strong correlation between modal responses is likely. The Root Sum Square method implies no correlation between the responses of the different modes, the maximum of each mode is independent of the maximum in other modes. In a uniform moment resisting frame undergoing a shear-type sway deformation the natural frequencies of free vibration increase roughly in the ratios of $1: 3: 5: 7: 9$. etc. and whilst the relative ratios between the frequencies of the higher modes tend towards 1.0 the contributions of these higher modes is rapidly diminishing because their Participation Factors become smaller with increasing mode number.

In three-dimensional structures, different modes in different directions may have very similar frequencies. If one of these modes is strongly excited by the earthquake at a given instant then the other mode, with a similar frequency, is also likely to be strongly excited at the same instant. In these cases Root Sum Square combinations have been shown to give nonconservative estimates of the maximum likely response.

With an increasing realisation that three-dimensional analyses were important in the response of real structures to earthquake excitation and the increasing concern of torsional behaviour, improvements in the modal combination methods were sought. For very short period structures where all the natural frequencies are low, and are therefore, in an absolute sense, close together, the few modes were often combined by taking the maximum response as the sum of the absolutes of the modal responses. In these structures, which are inherently massive, the excessively conservative nature of the combinations is unlikely to be a problem. In the 1972 Los Angeles proposal [Los Angeles, 1972] it was suggested that the worst of the SRSS of a minimum of three modes or the sum of the absolutes of any two modes be used for design. In a three dimensional structure it is likely that natural frequencies of modes in one translational direction will be similar to the natural frequencies of modes in the orthogonal translational direction or to the natural frequencies of the torsional modes.

Other modal combination methods that have been proposed are, in general, all related to the statistical combination of natural mode responses when the structure is subjected to a white noise excitation. It has been shown that these methods give reasonable combinations when applied to earthquake excitation. Similarly, the method proposed by Humar was initially developed for the torsional response of structures subjected to lateral ground excitation.

All the modal combination methods may be expressed in the form

$$
R_{\max }=\sqrt{\left(\sum_{i} \sum_{j} R_{i \max } \rho_{i j} R_{j \max }\right)}
$$

where $\rho_{i j}$ is the correlation coefficient which varies from combination method to combination method.

CQC [Wilson et al, 1981] (Complete Quadratic Combinations).

$$
\rho_{i j}=\frac{8 \sqrt{\lambda_{i} \lambda_{j} \omega_{i} \omega_{j}}\left(\lambda_{i} \omega_{i}+\lambda_{j} \omega_{j}\right) \omega_{i} \omega_{j}}{\left(\omega_{i}^{2}-\omega_{j}^{2}\right)^{2}+4 \lambda_{i} \lambda_{j} \omega_{i} \omega_{j}\left(\omega_{i}^{2}+\omega_{j}^{2}\right)+4\left(\lambda_{i}^{2}+\lambda_{j}^{2}\right) \omega_{i}^{2} c}
$$

where $\lambda_{i}$ and $\lambda_{j}$ are the fractions of critical damping in the $i$ th and $j$ th modes and $\omega_{i}$ and $\omega_{j}$ are the natural circular frequencies of the modes. Further discussion of this method may be found in the text by Clough and Penzien [Clough 1993]. 
DSC [Rosenblueth and Elorduy, 1969] (Double Sum Combination)

$$
\rho_{\mathrm{ij}}=\frac{1}{\left[1+\left(\frac{\left(\omega_{\mathrm{i}}^{\prime}-\omega_{\mathrm{j}}^{\prime}\right)}{\left(\lambda_{\mathrm{i}}^{\prime} \omega_{\mathrm{i}}+\lambda_{\mathrm{j}}^{\prime} \omega_{\mathrm{j}}\right)}\right)^{2}\right]}
$$

where

$$
\begin{gathered}
\omega_{i}^{\prime}=\omega_{i} \sqrt{1-\left(\lambda_{i}^{\prime}\right)^{2}} \\
\lambda_{i}^{\prime}=\lambda_{i}+\frac{2}{S \omega_{i}}
\end{gathered}
$$

$\mathrm{S}$ is the Time Duration of the White Noise segment of the earthquake record. For actual records, for example, the duration of the strong motion segment characterized by extremely irregular accelerations of roughly equal intensity should be taken.

Humar [Humar, 1984]. Here $\rho_{i j}$ is as for DSC with $S=$ infinity, i.e. $\lambda_{i}{ }^{\prime}=\lambda_{i}$ and if $\lambda_{i}=\lambda_{j}=\lambda$ (the usual assumption) then

$$
\rho_{\mathrm{ij}}=\frac{1}{\left[1+\left(\frac{\sqrt{1-\lambda^{2}}}{\lambda}\left(\frac{\omega_{\mathrm{i}}-\omega_{\mathrm{j}}}{\omega_{\mathrm{i}}+\omega_{\mathrm{j}}}\right)\right)^{2}\right]}
$$

and if $\lambda$ is much less than 1.0 then

$$
\rho_{i j}=\frac{1}{\left[1+\left(\frac{1}{\lambda}\left(\frac{\omega_{i}-\omega_{j}}{\omega_{i}+\omega_{j}}\right)\right)^{2}\right]}
$$

which was a mid-1980s proposal for the revision of NZS 4203 .

Gupta and Cordero [Gupta, 1990]. Proposed a modification to the DSC rule where $\rho_{\mathrm{ij}}$ is given by

$$
\rho_{\mathrm{ij}}=\frac{1}{\left[1+\left(\frac{\sqrt{1-\lambda^{2}}\left(\omega_{\mathrm{i}}-\omega_{\mathrm{j}}\right)}{\left(\lambda \omega_{\mathrm{i}}+\lambda \omega_{\mathrm{j}}+\mathrm{c}_{\mathrm{ij}}\right)}\right)^{2}\right]}
$$

where

$$
c_{i j}=(0.16-0.5 \lambda)\left(1.4-\left|\omega_{i}^{2}-\omega_{j}^{2}\right|\right) \geq 0.0
$$

This method produces greater values of the correlation coefficient when the two frequencies are very close but reduces to the CQC or the Humar rules as the frequency difference increases. Gupta also suggests a modification to all of the combination formulae when the damping is different in the different modes. This effect tends to reduce the correlation coefficients but in most code models all modes have the same fractions of critical viscous damping. The Gupta approach is not shown in Table 1 as the coefficient $c_{i j}$ is not dependent on only the frequency ratio, but has a constant part independent of all frequencies.

In all of these modal combination methods, $\rho_{\mathrm{ij}}$ tends to 0.0 as $\omega_{i}$ becomes very different from $\omega_{j}$, i.e.

$$
0 \leq \rho_{\mathrm{ij}} \leq 1.0
$$

Root-Sum-Square implies $\rho_{\mathrm{ii}}=1.0$ and $\rho_{\mathrm{ij}}=0.0$ for $i \neq j$ and therefore it would be possible to have a computer program to cover all of these combination methods, SRSS, CQC, DSC Humar and Gupta with the only difference being in the choice of the correlation coefficients $\rho_{\mathrm{ij}}$.

Table 1 shows the correlation coefficients for the different modal combination methods for a structure having $5 \%$ viscous damping in all modes. For the DSC methods, the product of the duration of strong shaking $\mathrm{S}$ times the lower natural circular frequency $\omega$ equals 30,60 and 120 respectively. For the Humar method $\mathrm{S}$ is equivalent to infinity.

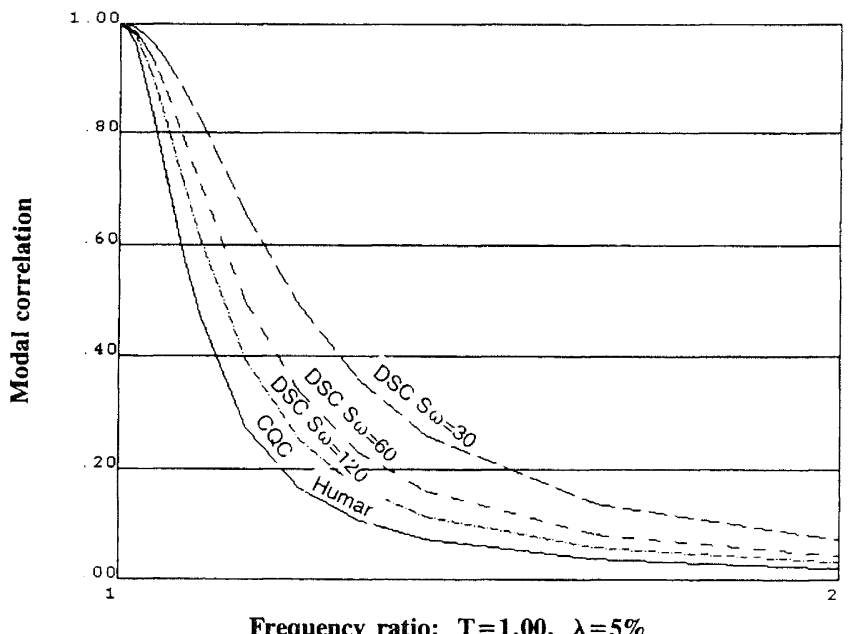

Figure 7. Modal Correlation Coefficient versus Frequency Ratio.

Figure 7 shows how the correlation coefficients change with the ratio of the frequency between any two modes and show that once the frequencies of the two modes differ by more that about $20 \%$ the effects of the correlation are insignificant. The only way to estimate the correctness of any modal combination method would be to compute the response using the response spectrum for a given earthquake and then carry out a elastic time-history analysis to the same earthquake excitation with the same excitation orientation and compare these responses with the maximum responses from the modal combination method. This would, in the view of the author, be about the only practical use, in a general seismic design, of elastic time-history analyses.

In the use of these statistical combination methods. the modal responses should be the final response required such as the displacements, the inter-storey drifts, the inter-story shears, the base shear, the axial forces, the bending moments or member stresses. No further combination of responses should be undertaken after the modal results are combined. This means that if the longitudinal stress is required in a column then one should not obtain the axial forces and bending moments on each column, carry out the modal combinations of these actions and then use the SRSS etc. values of the axial forces and bending moments to obtain the longitudinal stresses in the column. Rather, one should obtain the longitudinal stress in the column for each mode using the modal axial forces and bending moments and then carry out the combinations on the modal longitudinal stresses. 
Table 1. Modal Correlation Coefficients.

\begin{tabular}{||c|c|c|c|c|c|}
\hline $\begin{array}{c}\text { Period } \\
\text { Ratio }\end{array}$ & CQC & $\begin{array}{c}\text { DSC } \\
\text { S } \omega_{i}=30\end{array}$ & $\begin{array}{c}\text { DSC } \\
\text { S } \omega_{i}=60\end{array}$ & $\begin{array}{c}\text { DSC } \\
\text { S } \omega_{i}=120\end{array}$ & Humar \\
\hline 1.000 & 1.000 & 1.000 & 1.000 & 1.000 & 1.000 \\
\hline 0.990 & 0.995 & 0.998 & 0.996 & 0.994 & 0.990 \\
\hline 0.980 & 0.970 & 0.992 & 0.985 & 0.977 & 0.961 \\
\hline 0.970 & 0.928 & 0.983 & 0.967 & 0.950 & 0.915 \\
\hline 0.960 & 0.872 & 0.970 & 0.943 & 0.914 & 0.857 \\
\hline 0.950 & 0.807 & 0.953 & 0.912 & 0.870 & 0.792 \\
\hline 0.940 & 0.739 & 0.932 & 0.876 & 0.821 & 0.723 \\
\hline 0.920 & 0.603 & 0.882 & 0.795 & 0.715 & 0.590 \\
\hline 0.900 & 0.485 & 0.882 & 0.706 & 0.610 & 0.474 \\
\hline 0.850 & 0.279 & 0.653 & 0.498 & 0.394 & 0.276 \\
\hline 0.800 & 0.168 & 0.491 & 0.340 & 0.254 & 0.168 \\
\hline 0.750 & 0.108 & 0.360 & 0.233 & 0.169 & 0.109 \\
\hline 0.700 & 0.072 & 0.261 & 0.162 & 0.116 & 0.074 \\
\hline 0.600 & 0.035 & 0.138 & 0.083 & 0.059 & 0.038 \\
\hline 0.500 & 0.019 & 0.074 & 0.045 & 0.033 & 0.022 \\
\hline 0.400 & 0.010 & 0.041 & 0.025 & 0.019 & 0.013 \\
\hline 0.300 & 0.005 & 0.022 & 0.015 & 0.011 & 0.009 \\
\hline 0.200 & 0.002 & 0.012 & 0.008 & 0.007 & 0.006 \\
\hline 0.100 & 0.001 & 0.006 & 0.005 & 0.004 & 0.004 \\
\hline 0.010 & 0.000 & 0.003 & 0.003 & 0.003 & 0.003 \\
\hline
\end{tabular}

Whatever response $R_{i}$ is being computed, be it Base Shear, overturning Moment, Displacement, Bending Moment, Shear force, Axial Force, member stress etc., the quantity must be found for $\mathrm{EACH}$ mode BEFORE the combination method is used.

\section{DESIGN CONSIDERATIONS}

All of the preceding discussion has been related to linearly elastic structures undergoing small displacements. In most seismic codes, design to resist earthquake excitation implies a degree of ductile behaviour in the structures so that they exhibit a tough rather than brittle behaviour under a major earthquake. Such a ductile structure, at the design level of response, is no longer linearly elastic and thus the Principle of Superposition is no longer valid and modal analysis methods are not applicable. The inelastic methods of dynamic analysis are usually based on deterministic time-history analyses of the structure subjected to known ground motions. These methods are costly in data preparation in that a large amount of data is required and this is further complicated by the fact that all the data is not available until the design is complete. The analyses are also expensive, the computer models of the structural members require a level of skill in their use, and as yet, there is not a great choice in the available software. A level of skill is also required in interpreting the results. A major limitation is that individual earthquake accelerograms have to be used and the choice of appropriate accelerograms is difficult to relate to the design spectra provided in the design codes. These aspects will be covered in a subsequent paper.

In general, designers prefer to use elastic analyses for seismic design and apply appropriate modification factors to adjust the solutions to allow for the inelastic behaviour of the structures. In seismic design, allowances for these inelastic effects are made by modifying the elastic response spectra to get an inelastic design response spectra.

\section{Inelastic Design Spectra.}

The inelastic design spectra used by most design codes are generated from the elastic spectra using the Equal Displacement and Equal Energy concepts developed over the past three decades. An inelastic structure subjected to a design level earthquake is assumed to sustain a structural displacement ductility of $\mu$ where $\mu$ is defined as the ratio of the inelastic displacement $\Delta_{u}$ of the structure to its yield displacement $\Delta_{y}$ 
The concept of the equal displacement principle appears to date from a paper by Newmark [Newmark, 1960] at the 2nd World Conference on Earthquake Engineering, Tokyo, 1960. It was observed in a series of inelastic analyses that the inelastic structures had similar magnitudes of maximum displacement to those of identical structures which were constrained to remain linearly elastic. Assuming that this concept has some validity, in general, then an elastic structure has approximately the same displacement $\Delta_{\mathrm{e}}$ as the $\Delta_{\mathrm{u}}$ of a yielding structure when subjected to the same earthquake excitation. If a single degree of freedom inelastic system sustains a displacement ductility of $\boldsymbol{\mu}$ when subjected to the earthquake excitation, then from Figure 8, the inertia force, or base shear, generated in an elastoplastic single degree of freedom system is $1 / \mu$ of that in the matching elastic system.

For systems with very short natural periods, and in particular as the natural periods tends to zero, both inelastic and elastic systems appear to undergo equal accelerations and hence the forces generated in the systems are similar. This implies that the inelastic system with a ductility of $\mu$ undergoes a

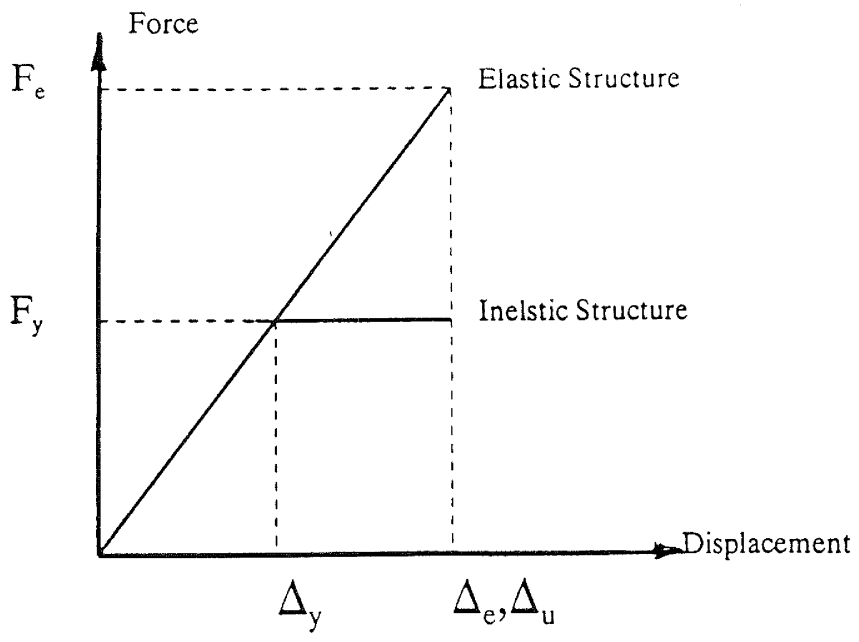

Figure 8. Equal Displacement Concept. displacement $\boldsymbol{\mu}$ times that of the elastic system. For systems with a natural period in an intermediate range the concept of equal energies or equal velocities has become accepted.

In the case of equal energies the areas under the elastic and inelastic force displacement plots are equal. This means that the ratio of the inelastic force to the elastic force $R$ is given by

$$
\mathrm{R}=\frac{\text { Inelastic Force }}{\text { ElasticForce }}=\frac{1}{\sqrt{2 \mu-1}}
$$

and the ratio of the inelastic structure displacement to the elastic structure displacement is given by

$$
\frac{\Delta_{u}}{\Delta_{e}}=\frac{\mu}{\sqrt{2 \mu-1}}
$$

These three principles have been adopted in the modifications of elastic response spectra for application to ductile structures. The application is most readily apparent in the tri-partite spectra used in ATC-3 and most other U.S. codes. Figure 10 is one of the design spectra from NZS 4203 showing how the

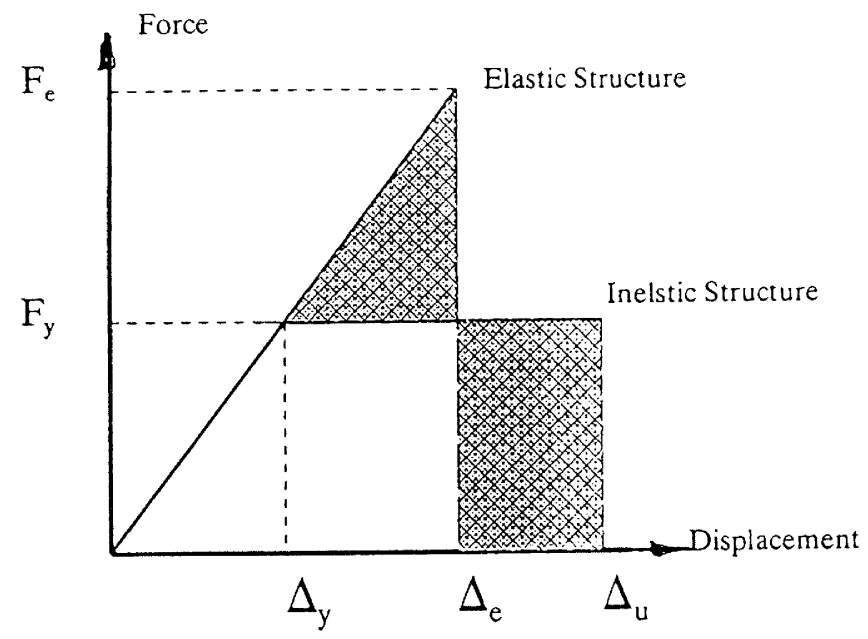

Figure 9. Equal Energy Concept.

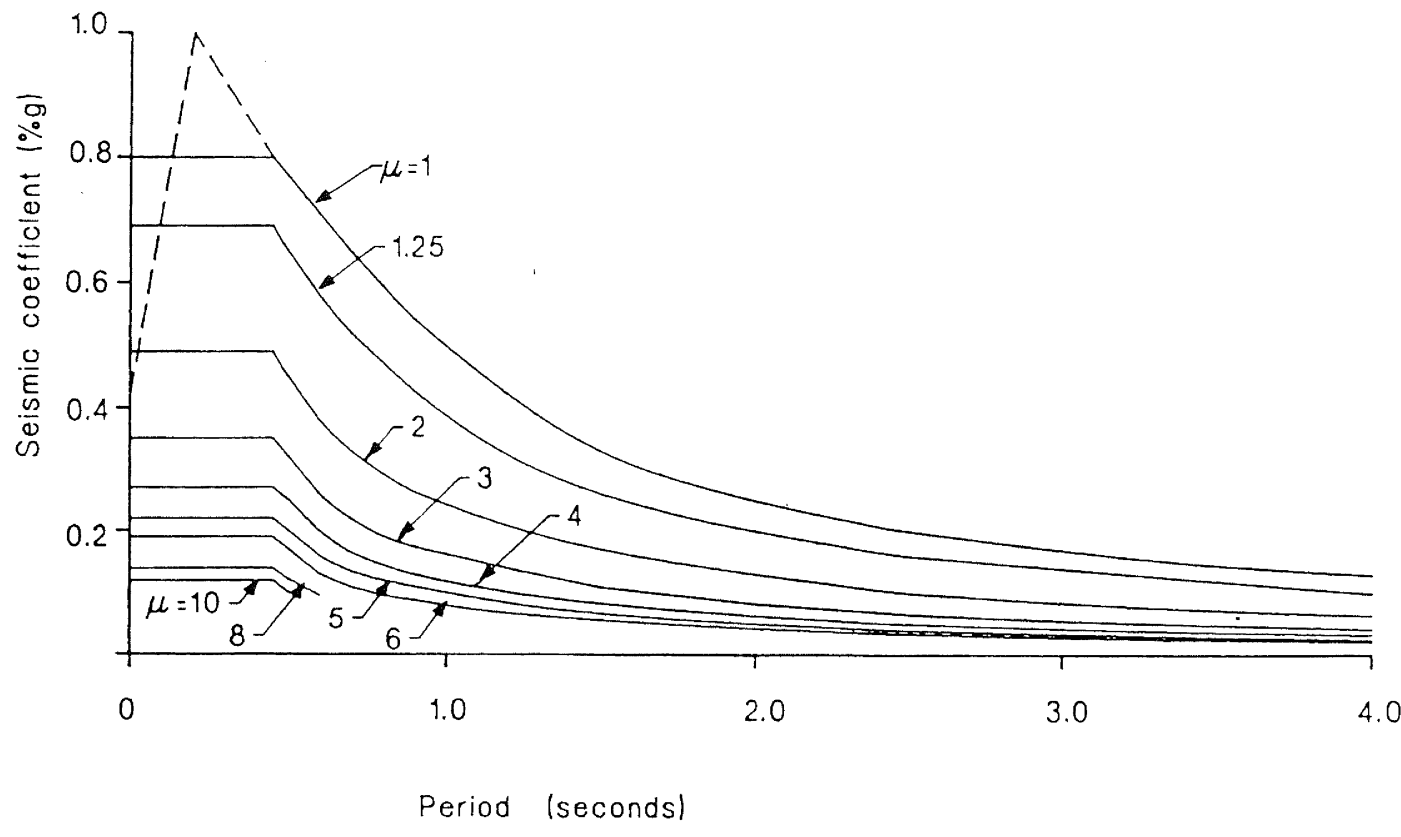

Figure 10. Basic seismic hazard acceleration coefficient for intermediate soil sites. 
elastic design spectra are modified to allow for ductile behaviour.

\section{MODELLING OF THE STRUCTURE}

\section{Effective Modulus for Reinforced Concrete Structures.}

Experimental work on reinforced and prestressed concrete bridges on the West Coast [Moss, 1979] has indicated that the effective modulus of elasticity of the concrete was somewhat greater than recommended design values. In order to match the experimental frequencies of free vibration and mode shapes over a range of modes, computer studies had to use values increased by approximately $20 \%$ for the reinforced concrete and approximately $40 \%$ for the prestressed concrete when compared with the design values. The model of the bridge assumed that the full cross-section was intact and all components acted as a unit even though there was some evidence that there was discontinuity between the precast and in-situ concrete. If this discontinuity was also allowed for then it is implied that the effective moduli may have been even greater. The stiffness of concrete does increase with age but design values are often based on the 28 day strength.

\section{Cross-Section Properties.}

The values for the section properties used during the analysis should represent the likely properties exhibited by the structure during the earthquake, whilst remaining elastic as the inelastic effects are taken into account in modifying the spectral values used in the lateral load analysis. This means that to gauge the inelastic response of concrete structures to rigorous shaking the properties assumed should not be those of pristine un-cracked members but should represent the effects of cracking, averaged out in some way along the member. This means that in reinforced concrete structures, different properties should be used in the analyses for a serviceability limit state than those which are used in analyses for the ultimate limit state. One should also allow for shear deformations if these are felt to be significant, particularly if the beams are short and deep such as in coupling beams of coupled walls, wall members and in spandrel beams.

The analysis should also take into account representative parts of the floor slab in estimating girder flexural stiffness. It must be stressed that in real structures the effective second moment of area will vary along the member's length depending on the amount of cracking and the sign of the curvature at points along the member. However, this will vary as the direction of loading changes. Most current analysis techniques assume that an averaging of the second moments of area will be satisfactory. As will be seen later, the significance of accuracy in predicting stiffness diminishes when inelastic response is to be evaluated.

The commentary to the latest revision of the New Zealand Concrete Code, NZS 3101, provides some guidance to engineers in the selection of effective section properties and Table 2 presents some of these recommendations.

\section{End Blocks.}

Assumptions in respect of rigid, or semi-rigid, end-blocks of members can have a significant effect on the stiffness of the frame, its natural frequencies of free vibration and on the response of the structure to dynamic excitation. Some analyses have indicated a decrease in the natural periods of the order of
$10 \%$ to $20 \%$ when member rigid end-blocks were included. This will be most marked where coupling beams frame into wide members such as structural walls and columns connect to spandrel beams. The computational cost of modelling rigid end-blocks is negligible and programs should incorporate such features. In reinforced concrete frames subjected to lateral forces, very large shear stresses and hence shear strains are developed in the beam-column joints. In such cases it is best to remove the presence of end-blocks.

Modelling can be considerably enhanced if the analysis program also considers lateral offsets as well as rigid endblocks. In frames with different girder depths in different spans, the locations of the neutral axes of the girders relative to the floor level will not be constant. With a lateral off-set the nodes, or frame joints, may be considered to be at floor level and not at the girder mid-depth as is assumed in most current analyses. In reinforced concrete structures subjected to large lateral forces and in steel frames with bolted connections, joint, or panel, flexibility may also need to be considered.

\section{Mass Representation.}

For most building structures a lumped mass model, usually with the whole storey mass lumped at the floor level, is generally all that is required. In a two-dimensional analysis the floor mass provides a single degree of freedom at each floor level. For a three-dimensional analysis, this mass acting in two orthogonal horizontal directions together with a rotational inertia about a vertical axis, usually through the centre of mass on the floor, is adequate provided that the floor diaphragm can be considered rigid in its own plane. If the displacements of each floor are not those of the centre of mass, a coupling of the inertia terms will occur. Some of the more recent computer programs assume displacement degrees of freedom to be those of an arbitrary point on the floor plan, though most current programs seem to require that the displacement degrees of freedom are those of the centre of mass which results in a diagonal mass matrix. The rotational inertia of the floor is that of the floor rotating as a rigid body about the vertical axis. The expressions for the inertia terms are found in most texts on dynamics and engineering mechanics [Clough, 1992]. If the code eccentricity of mass is used then the rotational inertia of the floor should be adjusted using the parallel axis theorem. NZS 4203 allows the designer to treat the rotational inertia as a constant when the centre of mass is shifted.

\section{Foundation Compliance.}

Most structures are located on a foundation medium that is not rigid. Not withstanding this fact, at the present time most analyses of structures subjected to earthquake excitation are analyzed assuming that they are located on an infinitely rigid foundation material. An allowance for foundation compliance, which is covered in many texts on soil-structure interaction or foundation design, and which may be modelled by the judicious use of springs and dashpots and/or masses, can make a significant change in the natural frequencies of free-vibration. This will affect the lateral forces determined from the response spectra. The effect is likely to most marked in the fundamental modes which make the major contribution to the inertial forces and also to the lateral displacements of the structure. There are research investigations under-way to study the base-isolation effects that may be available to the structure from its flexible foundations [Ahn and Gould, 1990]. 
Table 2. Effective Section Properties.

\begin{tabular}{|c|c|c|c|c|}
\hline \multirow[t]{2}{*}{ Type of member } & \multirow{2}{*}{$\begin{array}{l}\text { Ultimate Limit } \\
\text { State }\end{array}$} & \multicolumn{3}{|c|}{ Serviceability Limit State } \\
\hline & & $\mu=1.25$ & $\mu=\mathbf{3}$ & $\mu=6$ \\
\hline \multicolumn{5}{|l|}{ 1.Beams } \\
\hline $\begin{array}{l}\text { (i) Rectangular } \\
\text { beams }\end{array}$ & $0.40 \mathrm{I}_{\mathrm{g}}$ & $\mathrm{I}_{\mathrm{g}}$ & $0.70 \mathrm{I}_{\mathrm{g}}$ & $0.40 \mathrm{I}_{\mathrm{g}}$ \\
\hline (ii) $\mathrm{T}, \mathrm{L}$ beams & $0.35 \mathrm{I}_{\mathrm{g}}$ & $\mathrm{I}_{\mathrm{g}}$ & $0.60 \mathrm{I}_{\mathrm{g}}$ & $0.35 \mathrm{I}_{\mathrm{g}}$ \\
\hline \multicolumn{5}{|l|}{ 2.Columns } \\
\hline (i) $P>0.5 \mathrm{f}_{\mathrm{c}} \mathrm{A}_{\mathrm{g}}$ & $0.80 \mathrm{I}_{\mathrm{g}}$ & $I_{g}$ & $0.90 \mathrm{I}_{\mathrm{g}}$ & $0.80 \mathrm{I}_{\mathrm{g}}$ \\
\hline (ii) $P=0.2 \mathrm{f}_{\mathrm{c}} \mathrm{A}_{\mathrm{g}}$ & $0.60 \mathrm{I}_{\mathrm{g}}$ & $\mathrm{I}_{\mathrm{g}}$ & $0.80 \mathrm{I}_{\mathrm{g}}$ & $0.60 \mathrm{I}_{\mathrm{g}}$ \\
\hline (iii) $P=-0.05 f_{c} A_{g}$ & $0.40 \mathrm{I}_{\mathrm{g}}$ & $I_{g}$ & $0.70 \mathrm{I}_{\mathrm{g}}$ & $0.40 \mathrm{I}_{\mathrm{g}}$ \\
\hline \multicolumn{5}{|l|}{ 3.Walls } \\
\hline (i) $P=0.2 f_{c} A_{g}$ & $0.45 \mathrm{I}_{\mathrm{g}} ; 0.80 \mathrm{~A}_{\mathrm{g}}$ & $\mathrm{I}_{\mathrm{g}} ; \mathrm{A}_{\mathrm{g}}$ & $0.70 \mathrm{I}_{\mathrm{g}} ; 0.90 \mathrm{~A}_{\mathrm{g}}$ & $0.45 \mathrm{I}_{\mathrm{g}} ; 0.80 \mathrm{~A}_{\mathrm{g}}$ \\
\hline (ii) $\mathrm{P}=0.0$ & $0.25 \mathrm{I}_{\mathrm{g}} ; 0.50 \mathrm{~A}_{\mathrm{g}}$ & $\mathrm{I}_{\mathrm{g}} ; \mathrm{A}_{\mathrm{g}}$ & $0.50 \mathrm{I}_{\mathrm{g}} ; 0.75 \mathrm{~A}_{\mathrm{g}}$ & $0.25 \mathrm{I}_{\mathrm{g}} ; 0.50 \mathrm{~A}_{\mathrm{g}}$ \\
\hline (iii) $\mathrm{P}=-0.1 \mathrm{f}_{\mathrm{c}} \mathrm{A}_{\mathrm{g}}$ & $0.15 \mathrm{I}_{\mathrm{g}} ; 0.30 \mathrm{~A}_{\mathrm{g}}$ & $\mathrm{I}_{\mathrm{g}} ; \mathrm{A}_{\mathrm{g}}$ & $0.40 \mathrm{I}_{\mathrm{g}} ; 0.65 \mathrm{~A}_{\mathrm{g}}$ & $0.15 \mathrm{I}_{\mathrm{g}} ; 0.30 \mathrm{~A}_{\mathrm{g}}$ \\
\hline \multicolumn{5}{|l|}{ 4.Coupling beams "* } \\
\hline (i) Diagonally & $0.40 \mathrm{I}_{\mathrm{g}}$ & $\mathrm{I}_{\mathrm{g}}$ & $0.70 \mathrm{I}_{\mathrm{g}}$ & $0.40 \mathrm{I}_{g}$ \\
\hline reinforced & $1.7+2.7\left(\frac{\mathrm{b}}{\mathrm{L}}\right)^{2}$ & $1.7+1.3\left(\frac{\mathrm{h}}{\mathrm{L}}\right)^{2}$ & $1.7+2.7\left(\frac{h}{L}\right)^{2}$ & $1.7+2.7\left(\frac{\mathrm{h}}{\mathrm{L}}\right)^{2}$ \\
\hline (ii) Conventionally & $0.40 \mathrm{I}_{\mathrm{g}}$ & $\mathrm{I}_{\mathrm{g}}$ & $0.70 \mathrm{I}_{8}$ & $0.40 \mathrm{I}_{8}$ \\
\hline & $1+8\left(\frac{h}{L}\right)^{2}$ & $1+5\left(\frac{h}{L}\right)^{2}$ & $1+8\left(\frac{h}{L}\right)^{2}$ & $\overline{1+8\left(\frac{h}{L}\right)^{2}}$ \\
\hline
\end{tabular}

** The effects of shear deformations and strain penetration into walls along beam bars have been included.

\section{Soil-Structure Interaction.}

This section considers the foundation medium that, in general, lies below the structural foundation that may be considered as part of the structure proper. In most cases it is the soil medium between the structure and bed-rock.

Soil-structure interaction may be considered in one of several ways, the approach and the required accuracy depending on the relative lateral stiffnesses of the structure and its supporting soils.

The simplest approach is to ignore the phenomenon altogether. This is reasonable if the foundation material is stiff relative to the structure. This can be thought as being when the free-field vibration periods of the soil are short when compared with the lateral vibration natural periods of the structure.

If the foundation is complex and if the structure is of similar dimensions to the foundation, then the most appropriate method is to model the structure and the foundation together using finite element methods to model the continuum of the foundation. [Newmark, 1971, Idriss, 1980]. The foundation model in these cases should somehow represent the effects of radiation damping, the loss of energy which radiates out into the half-space of the foundation. Simple fixed boundary conditions applied to a finite element mesh act as reflective boundaries and special techniques, such as the "silent" boundary, usually using dashpot members, may be needed to represent the real semi-infinite nature of the real domain. Much work has recently been done on such problems in both the frequency and the time domains [Wolf, 1985, Zhao, 1990, Wolf, 1988].

In some cases the problem may be modelled by a multi-step solution [Newmark, 1971]. The foundation is modelled by finite element or simpler methods depending on whether or not it can be represented adequately as a one, two or three dimensional problem, to obtain the response of the free surface without the structure being present. This modifies the input motion for the effects of the underlying soil. The modified input can now be applied to the analysis of the structure which should account for any flexibility, or foundation compliance, that the foundation may provide for the structure. This may be done by a finite element or boundary element model [Zhao, 1990] or by impedance coefficients such as those suggested in [Newmark, 1971, Table 8.1] or [Idriss, 1980, Tables 1 and 2]. These allow for the flexible soil effects that may lead to a significant lengthening of the natural periods of the structure and which has been shown to have a major effect on the response of structures on soft foundations [Zhao, 1990]. 
Research by Zhao [1990] has shown that if the fundamental period of the structure is less than the fundamental period of the site, ignoring the soil-structure interaction may sometimes be dangerous while if the fundamental period of the structure is longer than the fundamental period of the site, the soilstructure effects would reduce the response of the structure even without the effects of radiation damping. If the fundamental periods of the structure and the site are similar, the displacement response of the structure relative to the free field responses are generally very large. If foundation compliance results in significant rocking of the structure, the result may be the inter-structure pounding observed in some earthquakes. It has been found that in most cases, the period shift is the more important factor affecting the structural response than is the energy dissipation by plastic deformations in the structure and radiation of energy into the flexible soil. Radiation damping is only significant when the natural frequency of the soil-structure system is greater than the natural frequency of the site itself.

It has been suggested that soil-structure interaction is not necessary for small to medium size buildings, or buildings that are built on very rigid soils (soils with a shear wave velocity greater than $700 \mathrm{~m} / \mathrm{s}$ ). Soil-structure interaction is necessary for tall and/or massive buildings (e.g. smoke stacks, nuclear power plants, offshore platforms), or buildings that are built on soft soils (soils with a shear wave velocity less than $200 \mathrm{~m} / \mathrm{s}$ ). SEASOC [1977] suggest that if the shear wave velocity divided by the product of the structure's fixed base fundamental natural period and the height to the centroid of the inertia forces in the fixed base first mode is less than 20 then soil-structure interaction studies should be carried out. Further suggestions on the modification to natural periods, inertia forces and displacements may be found in Chapter 6 of ATC-3 [ATC, 1978].

The NZS 4203 allows for the effect of the modification of the excitation by the soil foundation by providing a series of design spectra for hard, intermediate and soft soils. If these spectra are being used, the designer must still consider what degree of foundation compliance should be taken into account in modelling of the structure.

One of the greatest difficulties in allowing for the full soilstructure interaction model including the structure and, say, a finite element model of the foundation medium, is that the required input motion is that of the bed-rock at the bottom of the foundation medium. Most earthquake accelerograms have been recorded at the ground surface which is on top of a soil medium which will have modified in input bed-rock motion. The question now is, what is the bed-rock motion? The difficulty in trying to derive the bed-rock motion is that under strong lateral shaking the soil medium is likely to behave in a markedly non-linear manner. This difficulty in determining an appropriate bed-rock motion is most likely to occur in deterministic non-linear dynamic analyses. Where designers are using response spectral methods the effects are usually accounted for by developing different spectra for hard, intermediate and soft soil media as is shown in Figure 4.6.1 of NZS 4203.

\section{Sloping Foundations.}

Sloping ground may have a major impact on the torsional response of the structure to lateral ground excitation acting in a direction along the slope. The differing flexibilities of the structure on the up-hill and down-hill sides will cause a large shift of the centres of rigidity from those locations computed if one assumed that the base of the structure was level.

\section{Torsion.}

Torsion is considered in most analyses to be caused by the eccentricity of the mass with respect to the centres of rigidity in each storey.. This may be due to eccentricity of the mass, as the actual distribution of which at any particular time in the structure's life is unknown, or due to eccentricity in the stiffness or strength properties of the members. Even though the members may be meant to be symmetric in their stiffnesses, the variability in yield properties of ductile structures or of the material stiffnesses may mean that some eccentricity is likely under an earthquake excitation. Because of such uncertainties, most codes require the designer to consider some assumed torsion as being present in the structure. This is usually achieved by re-positioning the mass

Most computer programs do not consider the possibility of a torsional input ground motion. From a consideration of continuum mechanics, the concept of a torsional input ground motion is difficult to define but may be considered as the result of a travelling wave moving across the width of a structure with a reasonably wide foundation. In this case the effect of the torsion is to decrease the mean translational effects of the earthquake as not all the width of the structure is experiencing the same maximum ground translation at the same instant of time but the eccentrically applied translational accelerations will increase the response of the torsional modes. This torsional response may well increase the translational shear deformations in the perimeter members of the structure. It must be noted that in frames where torsional actions are being considered, the torsional and translational modes will not be distinct unless the building has two axes of symmetry in plan and the centres of mass coincide with the shear centres in each storey. Even in the case of such a structure, codes require that the centres of mass be moved to an eccentric position to allow for accidental torsional effects.

\section{Orientation of Seismic Motion.}

The designer should consider two orthogonal horizontal excitations. If thought necessary because of the presence of large beam spans, prestressed concrete girders or long cantilevers, a vertical excitation should also be considered. The most significant response, or the major torsional response in the structure may not be exhibited along the convenient horizontal $\mathrm{x}$ or $\mathrm{y}$ axes of the structure, particularly if the structure is asymmetric. The orthogonal horizontal axes should chosen to be the major and minor principal axes of the lateral stiffnesses of the structure, in plan.

\section{Concurrent Excitation.}

Most codes at the present time do not appear to consider concurrency of orthogonal earthquake excitation. Most consider a uni-directional excitation in any direction and require analyses be carried out separately in two orthogonal directions. A few codes, such as the Norwegian Offshore Requirements, require concurrent excitation, using SRSS combinations of the modal responses from the two orthogonal inputs. Other codes require the concurrent input from one direction together with $30 \%$ to $40 \%$ of the response from the orthogonal input. Arguments for the applicability of this approach may be found in the text by Clough and Penzien [Clough, 1993, Chapt. 26]. 
It is suggested [Clough, 1993] that if two concurrent inputs are being considered, the strongest component should be applied along the critical axis of the structure and the second component should have about $85 \%$ of the strength of the strongest component of the excitation. SEASOC [1977] gives the formula of $100 \%$ in one direction with $40 \%$ in the orthogonal directions.

The effects of concurrent loadings will be most significance in the design of columns and joints and will have a smaller effect on the design of beams unless the ensuing torsion will affect the flexural strength of the beams.

\section{Damping.}

It must be noted that the use of viscous damping is a mathematical convenience. The damping behaviour of real structures is not well understood and the damping mechanism is not known. Damping forces in structures probably follow a hysteretic pattern, i.e. they are functions of the displacements of the members and not velocities as is implied by viscous damping. There is also damping associated with the radiation of energy away from the structure into the foundation soils. To model damping correctly requires a non-linear material analysis with more elaborate member models than are currently available. There is also an enormous amount of research required to obtain the correct hysteretic models. All structures show a damped response to dynamic excitation. The amounts of damping are generally small and can thus be modelled reasonably well by a viscous damping model.

Damping in the structure is often assumed to be $5 \%$ of critical viscous damping in all modes. This is implicit in the response spectra provided in the NZS 4203 which provides only the $5 \%$ damped curve. If damping values other than the assumed $5 \%$ is more appropriate for the structure then the spectral values need to be adjusted for the expected level of viscous damping. The proposed Los Angeles code of 1972 gave tables of multiplying factors for Spectral Displacement, Pseudo Spectral Velocity and Spectral Acceleration for different damping levels. Some of the modal combination correlation factors are also functions of the amount of damping in each mode.

Table 3 shows the reduction factors to be applied to the tripartite undamped response spectrum to get the damped response spectra. [Los Angeles, 1972]

Table 4 [Berrill, 1980] gives multiplicative factors for spectra for $2 \%$ and $10 \%$ damping when the supplied spectra is for $5 \%$ of critical viscous damping. This would enable a designer to generate spectra for more or less fractions of critical damping than that provided by NZS 4203 if it is felt that the implied 5\% is not appropriate for the structure under consideration.

The values for the fractions of critical damping in structures suggested in some design tables have been increased to account for the reduction in the response due to inelastic behaviour in the structure. If the design response spectra have already been modified to account for this inelastic behaviour, then the use of these higher damping values would doubly account for the effects of the inelastic behaviour on the response.

Table 5 [SEASOC, 1977] gives typical damping values for various types of structure for varying levels of displacement. It should be noted that these fractions of critical damping seem to be applicable for carrying out elastic analyses and engineers are using the damping to reduce the response in a way to take account of inelastic effects. If an inelastic analysis is being performed then the inelastic effects should be taken into account in the hysteretic modelling and not by equivalent viscous damping effects.

It must be noted that certain types of structure, such as bare steel frames, prestressed bridges etc. may exhibit very low levels of viscous damping. As ductile behaviour is being accounted for in other ways, the damping must not be adjusted to account for energy dissipation by plastic work.

\section{Mode Shapes for Inelastic Structures.}

One of the most significant shortcomings of the modal methods of analysis is that the mode shapes of linear structures are not typical of the deflected shapes of inelastic structures. In elastic structures, the higher modes have a rapidly diminishing contribution to the displaced shape as the mode number increases. For inelastic structures, the higher mode effects become more significant. The first, or fundamental, natural period of free vibration lengthens and as a result, the fundamental mode may have a smaller contribution to the deflection and the deflected shape of the structure. In an elastic structure with reasonable uniform masses and stiffness distributions up the height of the structure, the maximum displacement profile is nearly linear with height. If the structure shows a ductile response, then the greatest inelastic deformations occur in the lower levels on the structure resulting in greater inter-storey drifts in these storeys. The inelastic response in the lower storeys limits the shear forces being transferred to the upper storeys and as a result, the maximum displacement profile becomes more parabolic in shape in that the inter-storey drifts near the top of the structure remain small while those in the lower storeys increase and may approach twice the average inter-storey drift. The result is that the modal participation factors, and in particular that of the fundamental mode, increase as the level of structural displacement ductility increases.

For this reason, there is some justifiable concern over the precise application of modal analysis techniques to ductile structures. The implied structural behaviour does not fit the linear elastic and small deflection assumptions implicit in the modal analysis method.

\section{Lack of Equilibrium following modal combinations.}

In a modal analysis, the forces in the frame associated with each mode shape are in equilibrium. However, when the forces or stresses etc. are combined by one of the modal combination methods to find the most likely maximum forces etc., the apparent equilibrium is lost. The combinations, such as SRSS, lose all sense of sign and hence the concept of which forces go with other forces to make up equilibrium. As far as the analysis is concerned, this causes no difficulty. The results give the most likely response in each member of the structure, which is what they are meant to do. This does, however, lead to some concern in capacity design strategies where an implicit equilibrium is used to provide protection for columns. In a capacity design, the girder moments from the modal combinations are factored up and the members designed. Once the over-strengths of the girders are known then the total overstrength moment must be distributed to the columns above and below the joint in some accepted manner. Traditionally, following a equivalent static analysis the joint moments are in equilibrium and the girder over-strength moments are distributed to the columns using the same proportions as 
Table 3. Spectrum Multipliers

\begin{tabular}{|c|c|c|c|}
\hline Damping \% & Acceleration & Velocity & Displacement \\
\hline 0 & 1.00 & 1.00 & 1.00 \\
\hline 0.5 & 0.91 & 0.90 & 0.88 \\
\hline 1 & 0.81 & 0.80 & 0.80 \\
\hline 2 & 0.67 & 0.70 & 0.72 \\
\hline 5 & 0.41 & 0.48 & 0.56 \\
\hline 7 & 0.30 & 0.38 & 0.48 \\
\hline 10 & 0.23 & 0.33 & 0.44 \\
\hline 15 & 0.20 & 0.30 & 0.41 \\
\hline 20 & 0.19 & 0.28 & 0.40 \\
\hline
\end{tabular}

Table 4. Multipliers for Differing \% Damping

\begin{tabular}{|c|c|}
\hline Percentage Critical Damping & Multiplier \\
\hline 2 & 1.4 \\
\hline 5 & 1.0 \\
\hline 10 & 0.8 \\
\hline
\end{tabular}

Table 5. Typical Values of Damping.

\begin{tabular}{|c|c|c|}
\hline Stress Level & Type of Structure & $\%$ Critical Damping \\
\hline $\begin{array}{l}\text { Low, much less than } 0.25 \\
\text { yield }\end{array}$ & $\begin{array}{l}\text { Steel,Concrete, } \\
\text { Wood, No cracking or joint } \\
\text { slip }\end{array}$ & $0.5-1.0$ \\
\hline $\begin{array}{l}\text { Working Stress, less } \\
\text { than } 0.5 \text { yield }\end{array}$ & $\begin{array}{l}\text { Welded Steel } \\
\text { Prestressed Conc. } \\
\text { Well Rein. Conc. } \\
\text { Cracked R.C. } \\
\text { Bolted/Rivetted Steel } \\
\text { Nailed/Bolted Timber }\end{array}$ & $\begin{array}{c}2.0 \\
3.0-5.0 \\
5.07 .0 \\
5.0-7.0\end{array}$ \\
\hline At or just below yield & $\begin{array}{l}\text { Welded Steel } \\
\text { Concrete (PC or RC) } \\
\text { Bolted/Rivetted } \\
\text { Steel,Bolted Wood } \\
\text { Nailed Wood }\end{array}$ & $\begin{array}{c}5.0 \\
7.0-10.0 \\
10.0-15.0 \\
15.0-20.0\end{array}$ \\
\hline $\begin{array}{l}\text { Beyond yield. } \\
\text { Permanent strain > } \\
\text { yield strain }\end{array}$ & $\begin{array}{l}\text { Welded Steel } \\
\text { Concrete } \\
\text { Bolted/rivetted steel and } \\
\text { wood }\end{array}$ & $\begin{array}{c}7.0-10.0 \\
10.0-15.0 \\
20.0\end{array}$ \\
\hline Rocking of Entire Structure & $\begin{array}{l}\text { Rock } v_{s}>1800 \mathrm{~m} / \mathrm{s} \\
\text { Firm } v_{s} \geq 600 \mathrm{~m} / \mathrm{s} \\
\text { Soft } v_{s}<600 \mathrm{~m} / \mathrm{s}\end{array}$ & $\begin{array}{c}2.0-5.0 \\
5.0-7.0 \\
7.0-10.0\end{array}$ \\
\hline
\end{tabular}


obtained from the static analysis. Following a modal analysis where the joint no longer shows a moment equilibrium, the girder over-strength moments could be distributed to the columns above and below the joint in the same ratio as the column moments from the modal analysis. The column moments from the modal analysis are not required, just the ratio between them.

\section{Base Isolation.}

Until recently, base isolation has only been used in design following lengthy deterministic time-history analyses because there were no simple reliable design methods available that would predict the distribution of forces through the structure when it was subjected to a lateral earthquake excitation. Recent work [Andriono and Carr, 1991], has led to the proposal of a relatively simple design method for base-isolated buildings. Further comprehensive discussion on base isolation techniques and design methods may be found in the recent book by Skinner et al [1993].

\section{Rocking Structures.}

The effects of base rocking is very similar to those effects caused by flexible foundation compliance except that in the case of rocking structures, a considerable increase of potential energy is made as the structure uplifts as it rocks to one side. This is potential energy is released as the structure returns to the upright position and there may be considerable forces developed, with an additional high frequency response, as the structure impacts on its foundation prior to rocking in the other direction.

\section{Modelling Irregular Structures.}

Podium structures should not cause any great difficulty in structural modelling. There will, however, be a discontinuity in the mass distribution and in the stiffnesses. In some structures, there may be the consideration given as to whether the floor diaphragm should be considered rigid in the neighbourhood of the tower where it meets the podium. A major difficulty will be experienced in attempting to reach a large fraction of the total mass participating in the modes considered as most of the mass will be near the base of the structure and will not strongly participate in the lower modes of free vibration. The difficulty is that the large mass of the podium undergoes only small displacements in the lower modes of free-vibration of the structure as these lower modes reflect the greater flexibility of the upper part of the structure. To achieve a $90 \%$ participation of the total mass may require a large number of modes to be considered. It may be more appropriate to relax the mass participation rule in these cases.

Structures which have unusual floor plans where the floor cannot be regarded as rigid in its own plane will cause difficulty in programs like ETABS and may require modelling in more general finite element or space frame programs to allow for the flexibility of the floor slab in its own plane.

Sloping ground will cause the greatest difficulty in modelling, especially in programs such as ETABS.

Hybrid structures should cause no real difficulty provided the programs used have the ability to model shear deformations, allow for rigid end-blocks, or have a suitable library of appropriate finite elements available. Again, consideration may be required as to whether the floor diaphragms may be considered as rigid in their own planes, particularly if the laterally stiff members are well separated from each other. The different deformation characteristics of wall and frame structures when subjected to lateral excitation may result in very large shear forces in the floor diaphragm between the walls and frames.

\section{Parts and Portions.}

Generally, response spectra should be produced for the section of the structure where the part or portion is to be located. This, in theory, may be obtained by locating a single degree of freedom oscillator in that part of the structure and subjecting the structure to the design ground motion. This analysis is then repeated as the natural frequency of the oscillator is varied. This is similar to getting the response spectra at the ground surface when the overlying soil medium is subjected to a bedrock motion. Should the part have a natural period similar to that of the structure, then a considerably enhanced response will be observed. It is for this reason that building codes apply multipliers to the design spectra when the design of parts and portions are being considered.

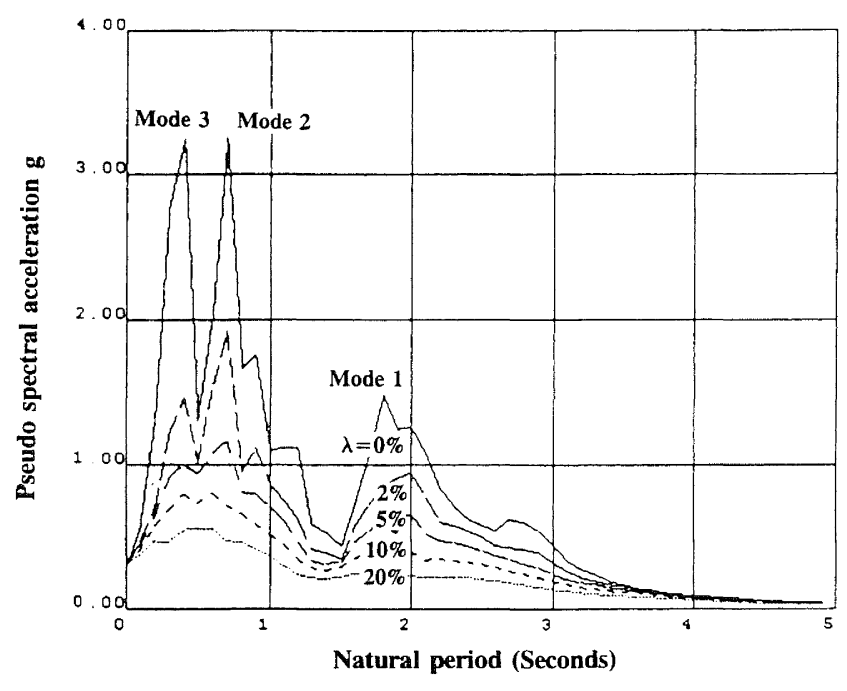

Figure 11. Acceleration Response Spectra at Floor 12.

Figure 11 shows the acceleration response spectra obtained from the total acceleration history for the top floor of a twelve storey frame subjected to the El Centro excitation shown in Figure 2. This spectra could be used for the design of a part to be located at the top of the frame and should be compared with the equivalent design spectra for the frame itself if it is to be subjected to the same motion and which is shown in Figure 4. The results of the displacements and forces in a part based on this spectra are almost identical with those of an analysis where the part was included in the structural model of the frame.

\section{EXTENDED MODAL ANALYSIS FEATURES.}

\section{Ritz Vectors.}

Ritz vectors have been used by engineers for a long time in dynamic and stability problems and they are the basis of the Rayleigh-Ritz method of reducing the number of degrees of freedom in a dynamic analysis. Traditional Ritz methods attempted to use a set of approximate mode shapes' as Ritz 
vectors and these methods, though satisfactory for a general dynamic solution, may use many vectors that are orthogonal to the response and thus have no contribution to the solution. In a more recent approach [Wilson et al, 1982] the vectors are recursively computed from the shape of the applied force vector. This means that all computed vectors contribute to the response and have a better chance of forming a set of mode shapes that make a significant contribution to the response of the structure. The disadvantage is that a new set of Ritz vectors has to be computed for each direction of excitation. The eigenvalue problem that has to be solved is of the order of the number of Ritz vectors used. These mode shapes have to be computed as the Ritz vectors do not have the property of orthogonality whereas the mode shapes of free-vibration do possess the property of orthogonality with respect to the mass and stiffness matrices. Without the use of the property of orthogonality, response spectra and modal methods cannot be used. The response spectra are computed for single-degree-offreedom systems and each natural mode of free vibration uncouples the multi-degree-of-freedom structural system into an equivalent one-degree-of-freedom system.

If the normal modes are used for dynamic analysis, then some of the mode shapes may be orthogonal to the excitation and those modes will have no significant contribution to the response. This sometimes makes it very difficult to determine how many modes should be included in the analysis. Even examining the modal participation factors is not always a good way of determining the significance of a mode as the forces are a function of the mode shape times the frequency squared and as the frequencies increase with mode number, the higher modes are more significant for forces than they are for displacements.

One suggestion made by E.L.Wilson et al. starts with the assumption that the excitation can be represented by the product of a spatial vector and a time function so that

$$
\{p(t)\}=\{f\} g(t)
$$

The first vector $\{x\}$, in the series of Ritz vectors is then obtained by solving the equation

$$
[K]\{x\}_{1}=\{f\}
$$

Vector $\{x\}_{1}$ which essentially represents the static response of the structure to the applied forces is then normalised. Wilson normalized the vector to be ortho-normal to the mass matrix but in the example here it may be normalized in any way that the user wishes.

Subsequent vectors in the series are members of the following Krylov series

$$
\{\mathrm{x}\}_{1},[\mathrm{~K}]^{-1}[\mathrm{M}]\{\mathrm{x}\}_{1},\left([\mathrm{~K}]^{-1}[\mathrm{M}]\right)^{2}\{\mathrm{x}\}_{1} \ldots\left([\mathrm{K}]^{-1}[\mathrm{M}]\right)^{\mathrm{j}}\{\mathrm{x}\}_{1}
$$

These vectors are obtained from the recurrence relationship

$$
[\mathrm{K}]\{\overline{\mathrm{x}}\}_{i}=[\mathrm{M}]\{\mathrm{x}\}_{\mathrm{i}-1} .
$$

Each vector $\left\{\bar{x}_{i}\right\}$ is then orthogonalized with respect to the vectors obtained earlier. The pure vector $\{x\}_{i}$ is obtained from the following relationship

where

$$
c_{j}=\frac{\{x\}_{j}{ }^{T}[M]\{\bar{x}\}_{i}}{\{x\}_{j}{ }^{\mathrm{T}}[M]\{x\}_{j}}
$$

The vector $\{\mathrm{x}\}_{\mathrm{i}}$ may now be normalized as for the earlier vectors. Suppose that the $M$ Ritz vectors have been generated as above, then the vectors may be arranged in the $N$ by $M$ matrix $[\mathrm{X}]$ where every column of the matrix is a Ritz vector.

The $\mathrm{N}$ degree of freedom equation of dynamic equilibrium

$$
[\mathrm{M}]\{\ddot{\mathrm{x}}\}+[\mathrm{C}]\{\dot{\mathrm{x}}\}+[\mathrm{K}]\{\mathrm{x}\}=\{\mathrm{p}(\mathrm{t})\}
$$

may be modified with the Ritz approximation

$$
\{x\}=[X]\{y\}
$$

where $\{y\}$ is a vector of generalized coordinates.

The transformed equation may be written as

$$
\left[\mathrm{M}^{*}\right]\{\ddot{y}\}+\left[\mathrm{C}^{*}\right]\{\dot{y}\}+\left[\mathrm{K}^{*}\right]\{\mathrm{y}\}=\left\{\mathrm{p}^{*}(\mathrm{t})\right\}
$$

where

$$
\begin{aligned}
& {\left[\mathrm{M}^{*}\right]=[\mathrm{X}]^{\mathrm{T}}[\mathrm{M}][\mathrm{X}]} \\
& {\left[\mathrm{C}^{*}\right]=[\mathrm{X}]^{\mathrm{T}}[\mathrm{C}][\mathrm{X}]} \\
& {\left[\mathrm{K}^{*}\right]=[\mathrm{X}]^{\mathrm{T}}[\mathrm{K}][\mathrm{X}]} \\
& \left\{\mathrm{p}^{*}(\mathrm{t})\right\}=[\mathrm{X}]^{\mathrm{T}}\{\mathrm{p}(\mathrm{t})\}
\end{aligned}
$$

Note that the $M$ by $M$ matrices $\left[\mathrm{M}^{*}\right],\left[\mathrm{C}^{*}\right]$ and $\left[\mathrm{K}^{*}\right]$ are fully populated matrices as the Ritz vectors $[\mathrm{X}]$ are not orthogonal with respect to the mass and stiffness matrices.

If the mode shapes $\{z\}$ and natural frequencies $\omega$ are found from the equation of free vibration, we obtain a new set of Ritz vectors $\left[\mathrm{X}^{0}\right]$ which are orthogonal to the mass and stiffness matrices, and they are assumed to be orthogonal to the damping matrix. At the same time, they are related to the form of the loading in that none of them will be orthogonal to the applied load

$$
\left[X^{0}\right]=[X][Z]
$$

If the transformed equation of equilibrium is now re-computed with the new Ritz vectors then the matrices $\left[\mathrm{M}^{*}\right],\left[\mathrm{C}^{*}\right]$ and $\left[\mathrm{K}^{*}\right]$ are now diagonal matrices and the response to each generalized degree of freedom may be found by, say, Response Spectra methods and then transformed back to the original coordinates $\{x\}$.

\section{Static Correction to Modal Analyses.}

The modal response of a structure in mode $i$ is given by the equation

$$
\ddot{y}_{i}+2 \lambda_{i} \omega_{i} \dot{y}_{i}+\omega_{i}^{2} y=\frac{p_{i}{ }^{*}(t)}{M_{i}^{*}}
$$

where $\lambda_{i}$ is the fraction of critical damping in the $i$ th mode, $\omega_{i}$ is the natural circular frequency (radians/second) of the $i$ th mode which has a mode shape vector $\left\{\phi_{i}\right\}$ and where $\mathrm{p}_{\mathrm{i}}{ }^{*}$ and $\mathrm{M}_{\mathrm{i}}^{*}$ are given by

$$
\begin{gathered}
\mathrm{p}_{\mathrm{i}}{ }^{*}(\mathrm{t})=\{\phi\}_{\mathrm{i}}^{\mathrm{T}}\{\mathrm{p}(\mathrm{t})\} \\
\mathrm{M}_{\mathrm{i}}{ }^{*}=\{\phi\}_{\mathrm{i}}^{\mathrm{T}}[\mathrm{M}]\{\phi\}_{\mathrm{i}}
\end{gathered}
$$


and the displacement $\{x\}$ of the structure is obtained by combining all $\mathrm{N}$ the modal contributions

$$
\{x\}=\sum_{i=1}^{N}\{\phi\}_{i} y_{i}
$$

If only $\mathrm{M}$ of the $\mathrm{N}$ modes are used then the $\mathrm{M}$ modes must include all the frequencies contained in $\{\mathrm{p}(\mathrm{t})\}$ that are significant [Humar,1990]. If the frequency $\omega_{i}$ of mode $i$ is much greater than the frequencies found in $\{p(t)\}$ then the response of that mode can be shown to be basically static. In the above equation of equilibrium for $y$, the last term on the left hand side will dominate the equation and the first two terms will become relatively insignificant. The equation above is used to solve the first $\mathrm{M}$ modes and the remaining values of $\mathrm{y}$ are found from

$$
\mathrm{y}_{\mathrm{i}}=\frac{\mathrm{p}_{\mathrm{i}}^{*}(\mathrm{t})}{\omega_{\mathrm{i}}{ }^{2} \mathrm{M}_{\mathrm{i}}^{*}}
$$

The total response can now be obtained but this is not very helpful in that all $\mathrm{N}$ mode shapes and frequencies have to be found to compute the solution.

$$
\{x\}=\sum_{i=1}^{M}\{\phi\}_{i} y_{i}+\sum_{i=M+1}^{N}\{\phi\}_{i} \frac{p_{i}^{*}}{\omega_{i}^{2} M_{i}^{*}}
$$

The solution $\{x\}_{\text {static }}$ can be defined as

$$
\{x\}_{\text {static }}=[K]^{-1}\{\mathrm{p}\}=\sum_{\mathrm{i}=1}^{\mathrm{N}}\{\phi\}_{\mathrm{i}} \frac{\mathrm{p}_{\mathrm{i}}^{*}}{\omega_{\mathrm{i}}^{2} \mathrm{M}_{\mathrm{i}}^{*}}
$$

The solution $\{x\}$ can then be rewritten as

or

$$
\{\mathrm{x}\}=\sum_{\mathrm{i}=1}^{\mathrm{M}}\{\phi\}_{\mathrm{i}} \mathrm{y}_{\mathrm{i}}+\{\mathrm{x}\}_{\text {static }}-\sum_{\mathrm{i}-1}^{\mathrm{M}}\{\phi\}_{\mathrm{i}} \frac{\mathrm{p}_{\mathrm{i}}{ }^{*}}{\omega_{\mathrm{i}}{ }^{2} \mathrm{M}_{\mathrm{i}}{ }^{*}}
$$

$$
\{x\}=\sum_{i=1}^{M}\{\phi\}_{i} y_{i}+[K]^{-1}\{p\}-\sum_{i=1}^{M}\{\phi\}_{i} \frac{P^{*}{ }_{i}}{\omega_{i}{ }^{2} M^{*}{ }_{i}}
$$

where the last two terms are the static correction to the response obtained with the first $M$ modes.

\section{ETABS MODELLING OF STRUCTURES}

The ETABS program is widely used by the engineering profession in design and in teaching, for the analysis of three dimensional buildings subject to earthquake excitation and has become almost the de-facto standard analysis software in New Zealand design offices. There are, however, a few points that may need consideration by the users of the program when modelling structures.

The major difficulties with program's structural model are:

1. The lack of compatibility between inter-connecting frames. Only the two horizontal displacement degrees of freedom and the rotation about the vertical axis are forced to be compatible between all frames at any floor level. A problem arises if, as was implied in the original TABS model, the structure is modelled as a series of inter-connecting plane frames which are then required to have the same lateral displacements at each floor. The result is that the interconnecting joints in each frame do not have compatible vertical displacements or the same rotations about horizontal axes. If the structure is modelled as a single three-dimensional frame or if there are several spatially isolated frames inter-connected only by the floor diaphragms there is no difficulty.

2. The program, at least in its earlier versions, cannot allow for in-plane flexibility of the floor diaphragms. This will cause some modelling problems where long narrow floors are encountered, or floors having an $\mathrm{L}$ or $\mathrm{U}$ shape in plan. Similar difficulties may be encountered in precast floors with a low inplane shear stiffness. These difficulties will be more significant in hybrid structures where the different deformation characteristics of wall and frame systems can result in large shear forces being transmitted in the floor diaphragms.

3. The program only allows the modelling of vertical columns. Some more recent structures have had raking columns.

4. Only horizontal floor systems are readily modelled which causes difficulty with parking structures and with sloping foundations. All columns are assumed to be connected at each floor level causing difficulties where some columns may extend over more than one storey before again being connected at a level.

5. Vertical inertias and rotational inertias about horizontal axes are not considered. For squat buildings this is not a problem but the lack of vertical inertial effects will affect the natural frequencies on tall narrow buildings and hence have an effect on the lateral response of the structure. Vertical earthquake excitations are not able to be considered.

6. Time-history analyses can be carried out for linear elastic structures but these are likely to be useful only in confirming the appropriateness of the modal combination methods used in the response spectra analyses unless one wishes to compute acceleration histories at upper floors in order to produce floor spectra.

\section{ACKNOWLEDGEMENTS}

The author wishes to acknowledge the help given by other members of the study group, Dr R.D. Sharpe, Dr B. Davidson and Mr G. Sidwell, for their deliberations on the points covered in the paper and to Prof. T. Paulay for his suggestions for improvement in its presentation.

\section{REFERENCES}

Ahn K. and Gould P. 1990. Aseismic Base Isolation Using Natural Elements in the Interactive Soil-pile-structure System, Struct. Div Report No.86, Department of Civil Engineering, Washington Univ. in St. Louis.

Andriono T. and Carr A.J. 1991. Reduction and Distribution of Lateral Seismic Inertia Forces on Base Isolated MultiStorey Structures. Bull. NZ Nat. Soc. Earthquake Eng. 24(3):225-237.

Andriono T. and Carr A.J. 1991. A Simplified Earthquake Resistant Design Method for Base Isolated Multi-Storey Buildings. Bull. NZ Nat. Soc. Earthquake Eng. 24(3):238250 . 
Applied Technology Council. 1978. ATC3-06, Tentative Provisions for the Development of Seismic Regulations for Buildings.

Berrill,J.,Priestley,M.J.N. and Chapman,H.E. 1980. Design Earthquake Loading and Ductility Demand. Bull. NZ Nat. Soc. Earthquake Eng. 13(3):232-241.

City of Los Angeles. 1972. Proposed Code Amendments, 1972. City of Los Angeles, Building and Safety Commission.

Clough, R.W. and Penzien, J. 1993. Dynamics of Structures. 2nd Edition, McGraw-Hill, New York. 738p.

Gupta, A.K. 1990. Response Spectrum Method In Seismic Analysis and Design of Structures. Blackwell Scientific, Cambridge, Mass., 170p

Humar, J.L. 1984. Design for Seismic Torsional Forces. Proc. Can. J. Civ. Eng. 11:150-163.

Humar, J.L. 1990. Dynamics of Structures. Prentice Hall, Englewood Cliffs, New Jersey, ISBN 0-13-222068-7. (See Chapter 13)

Idriss et al. 1980. Analysis for Soil-Structure Interaction Effects for Nuclear Power Plants. Report by Ad-Hoc Group on Soil Structure Interaction, Structural Division, ASCE.

Lysmer, J. 1978. Analytical Procedures in Soil Dynamics, Report No. UCB/EERC-78/29, College of Engineering, University of California, Berkeley.

Moss, P.J. and Carr, A.J. 1979. Vibration Tests on the Buller River Bridge at Westport. Research Report 79-16, Department of Civil Engineering, University of Canterbury, 33p.

Newmark, N.M. and Veletsos, A.S. 1960. Effect of Behaviour of Simple systems to Earthquake Motion. Proc. 2nd World Conf. on Earthquake Engineering. Tokyo, 11-18 July 1960 895-912.

Newmark and Rosenblueth. 1971. Fundamentals of Earthquake Engineering. Prentice Hall.
NZS 4203:1992. 1992. Code of Practice for General Structural Design and Design Loadings for Buildings. Volumes 1, The Code and Volume 2, The Commentary. Standards New Zealand, Wellington.

Rosenblueth, E. and Elorduy, J. 1969. Responses of Linear Systems to Certain Transient Disturbances, Proc. 4th World Conf. on Earthquake Engineering. Santiago, Chile.

SEAOSC. 1977. Seismic Analysis by Computer. Report by Electronic Computation Committee, Structural Engineers Association of Southern California.

Skinner, R.I. 1966. Earthquake-Generated Forces and Movements in Tall Buildings. Bulletin 166. NZ DSIR, Wellington.

Skinner, R.I., Robinson, W.H. and McVerry, G.H. 1993. An Introduction to Seismic Isolation. Wiley, Chichester, $354 \mathrm{p}$.

Wilson, E.L., Der Kiureghian, A., and Bayo, E.P. 1981. A Replacement for the SRSS Method in Seismic Analysis. Earthquake Engineering and Structural Dynamics 9:187-194.

Wilson E.L., Ming-wu Yuan and Dickens J.M. 1982. Dynamic Analysis by Direct Superposition of Ritz Vectors. $J$. Eq Eng. and Struct. Dyn. 10:813-821.

Wolf, J.P. 1985. Dynamic Soil Structure Interaction. Prentice Hall Inc., Englewood Cliffs, New Jersey.

Wolf, J.P. 1988. Soil-Structure Interaction Analysis in the Time Domain, Prentice-Hall, Englewood Cliffs, New Jersey.

Zhao, X., Seismic Soil-Structure Interaction, Ph.D Thesis, Department of Civil Engineering, University of Canterbury, 1990.

Zhao, X, Carr, A.J. and Moss, P.J., Soil-Structure Interaction Using Boundary Elements in the Time-Domain, Proc. 11th Australasian Conf. on the Mech. of Struct. and Mat., 1989 